\title{
Surface and interface of epitaxial CdTe film on CdS buffered van der Waals mica substrate
}

Y.-B. Yang, ${ }^{*}$ L. Seewald, ${ }^{*}$ Dibyajyoti Mohanty, ${ }^{+}$Y. Wang, ${ }^{\ddagger}$ L.H. Zhang, ${ }^{\S}$ K. Kisslinger, ${ }^{\S}$ Weiyu Xie, ${ }^{*}$ J. Shi, ${ }^{\ddagger}$ I. Bhat, ${ }^{+}$Shengbai Zhang, ${ }^{*}$ T.-M. Lu, ${ }^{*}$ and G.-C. Wang ${ }^{*}$

*Department of Physics, Applied Physics and Astronomy, and Center for Materials, Devices, and Integrated Systems, Rensselaer Polytechnic Institute, $1108^{\text {th }}$ Street, Troy, NY 12180-3950, ${ }^{+}$Department of Electrical, Computer and Systems Engineering, Rensselaer Polytechnic Institute, $1108^{\text {th }}$ Street, Troy, NY 12180-3950,

${ }^{\ddagger}$ Department of Materials Science and Engineering, Rensselaer Polytechnic Institute, $1108^{\text {th }}$ Street, Troy, NY 12180-3950,

${ }^{\S}$ Brookhaven National Lab, Center for Functional Nanomaterials, Upton, NY 11973

Correspondence: yunb.yang@gmail.com

\begin{abstract}
Single crystal CdTe films are desirable for optoelectronic device applications. An important strategy of creating films with high crystallinity is through epitaxial growth on a proper single crystal substrate. We report the metalorganic chemical vapor deposition of epitaxial CdTe films on the CdS/mica substrate. The epitaxial CdS film was grown on a mica surface by thermal evaporation. Due to the weak van der Waals forces, epitaxy is achieved despite the very large interface lattice mismatch between CdS and mica ( 21 - 55\%). The surface morphology of mica, CdS and CdTe were quantified by atomic force microscopy. The near surface structures, orientations and texture of CdTe and CdS films were characterized by the unique reflection highenergy electron diffraction surface pole figure technique. The interfaces of CdTe and CdS films and mica were characterized by X-ray pole figure technique and transmission electron microscopy. The out-of-plane and in-plane epitaxy of the heteroepitaxial films stack are determined to be CdTe(111)//CdS(0001)//mica(001) and $[\overline{1} 2 \overline{1}]_{\mathrm{CdTe}} / /[\overline{1} 100]_{\mathrm{CdS}} / /[010]_{\text {mica }}$, respectively. The measured photoluminescence (PL), time resolved PL, photoresponse, and Hall mobility of the $\mathrm{CdTe} / \mathrm{CdS} /$ mica indicate quality films. The use of van der Waals surface to grow epitaxial CdTe/CdS films offers an alternative strategy towards infrared imaging and solar cell applications.
\end{abstract}

Keywords: Heteroepitaxy, CdTe, van der Waals, RHEED, photoresponse 


\section{Introduction}

CdTe has become one of the most important materials in optoelectronic devices, ranging from infrared imaging to solar cell devices. CdTe has a direct band gap at $\sim 1.5 \mathrm{eV}$ and high absorption coefficients $\left(>5 \times 10^{5} \mathrm{~cm}^{-1}\right)$ for wavelengths in the solar spectrum. Quality of the CdTe films, in most cases the crystallinity, plays an important role in the performance of the devices. One of the most important strategies to create high crystallinity films is to grow them epitaxially on single crystal substrates. The techniques used to grow CdTe films are rich, including but not limited to molecular beam epitaxy[1, 2], e-beam evaporation[3], hot wall epitaxy[4], close space sublimation[5], high vacuum evaporation[6], chemical bath deposition[7], and metalorganic chemical vapor deposition[8]. Examples of single crystal substrates used are $\operatorname{Si}[2,4,9,10]$, $\mathrm{Ge}[1,3,5,8,11]$, CdTe[12, 13], CdS[12, 14], GaAs[8, 15-21], $\mathrm{Al}_{2} \mathrm{O}_{3}[22]$, and $\mathrm{SrTiO}_{3}[23]$. Epitaxial CdTe film has also been shown to grow on glass substrate using nanostructured buffer layer of $\mathrm{Ge}(111) / \mathrm{CaF}_{2}(111)$ [24]. Biaxial CdTe films have also been shown to grow on large grain biaxial $\mathrm{Ni}(100)$ foils $[25,26]$ and biaxial $\mathrm{CaF}_{2}(111)$ on glass substrate[27]. All these substrates used in the epitaxy growth are either bulk single crystals or epitaxial films that themselves are grown epitaxially on different bulk single crystals, biaxial foils or biaxial films on nanostructures.

In this work, we have adopted a different strategy to develop a relevant substrate for the epitaxial growth of CdTe films, namely the epitaxial CdS films grown on mica substrates through van der Waals epitaxy (vdWE). It has been suggested that substrate with weak van der Waals interaction at interfaces could be a promising strategy for the growth of epitaxial films [28] or nanostructures[29, 30], even when the film itself is non-layered in nature. Due to the weak van der Waals interactions, there exists a high tolerance for lattice mismatch between the films and the substrates and strain-free or nearly strain-free films can be achieved even under a large lattice mismatch. Various 3D nonplanar nanostructured semiconductors such as individual CdS and CdTe nanowires[31], tripods[32], and 2D nonlayered semiconductor $\mathrm{Pb}_{1-\chi} \mathrm{Sn}_{x}$ Se nanoplates [29] have been grown on mica substrates. Despite the large lattice mismatch between a 3D vertical nanowire and a mica substrate, the incommensurate and relaxed heterointerface have been mainly attributed to van der Waals epitaxy mechanism[33]. The finite size effect of the nanostructure substrate such as an island can also contribute to the interface lattice relaxation due to the absence of lateral constrain in the film deposited on the island, termed nanoheteroepitaxy[34]. For a 3D planar film such as CdS deposited on a van der Waals substrate, there is no finite size relaxation effect at the interface and the film is mainly controlled by the van der Waals forces[35, 36].

Additional advantages of mica are that flexible thin layers of mica can be easily cleaved and peeled off from the bulk mica. The cleaved surface forms a pseudo-hexagonal lattice of (001) orientation with large atomically smooth areas. Mica is also chemically inert $\left(\mathrm{K}_{2} \mathrm{O} \cdot \mathrm{Al}_{2} \mathrm{O}_{3} \cdot \mathrm{SiO}_{2}\right)$ and thermally stable up to about $700^{\circ} \mathrm{C}$. We chose $\mathrm{CdS}$ as the buffer layer since it has been widely used as the window layer in $\mathrm{CdTe} / \mathrm{CdS}$ solar cell applications[37]. We report our key contributions: (1) We succeeded in growing a stack of epitaxial CdTe/CdS films on mica. A continuous epitaxial CdS film was grown first through van der Waals interaction on a mica substrate by thermal evaporation without intentional heating of mica. This epitaxial CdS film was used as a buffer to grow a continuous epitaxial CdTe film by metalorganic chemical vapor 
deposition (MOCVD) at $400^{\circ} \mathrm{C}$. (2) We experimentally determined the epitaxial relationships between CdTe, CdS and mica using X-ray pole figures and determined the near surface texture of CdTe and CdS using transmission mode of reflection high energy electron diffraction (RHEED) surface pole figure analysis. The unique RHEED pole figure shows that the near surface texture $(\sim 20 \mathrm{~nm})$ of the $\sim 2 \mu \mathrm{m}$ thick CdTe film has a better quality than the average texture from the entire CdTe film indicating an improvement of the in-plane texture of CdTe away from the interface of CdTe and CdS. (3) Optical characterizations of CdTe/CdS/mica by steady-state photoluminescence (PL), time resolved PL, and photocurrent response time of a two-terminal device show the optical band gap and carrier lifetime of high-quality CdTe and CdS films. The optical bandgap of the CdTe/CdS film depends on the CdTe thickness and is consistent with an interface alloying of $\mathrm{CdS}_{x} \mathrm{Te}_{1-x}$. (4) The measured Hall mobility in the undoped epitaxial CdTe/CdS film is about $\sim 364 \mathrm{~cm}^{2} /(\mathrm{V} \bullet \mathrm{s})$ that is much higher than the reported $0.1-1 \mathrm{~cm}^{2} / \mathrm{V} \bullet$ s measured from polycrystalline CdTe/CdS solar cells. 


\section{Experimental}

\section{Thermal evaporation deposition of CdS on mica substrates}

The mica substrate was prepared by cleaving a thin layer from a mica $\left(\mathrm{K}_{2} \mathrm{O} \cdot \mathrm{Al}_{2} \mathrm{O}_{3} \cdot \mathrm{SiO}_{2}\right)$ slide of size $75 \mathrm{~mm} \times 25 \mathrm{~mm} \times 0.26 \mathrm{~mm}$ (SPI Supplies, Grade V-4). Using a razor blade one can separate a thin sheet ( $100-200 \mu \mathrm{m}$ in thickness) from the mica slide, which can be further peeled off by a pair of tweezers. This process was used so that the sample surface was "fresh" when it was loaded in the deposition chamber shortly after it was peeled off.

The CdS film was thermally evaporated on the mica substrate in a Denton Explorer 14 Coating System. The base pressure of the chamber was about $9 \times 10^{-7}$ Torr. During the deposition the mica substrate was not intentionally heated. The mica temperature was monitored using a pair of K-type thermocouple wires attached behind the sample. The CdS chunk pieces (3 - $12 \mathrm{~mm}$, 99.999\% purity from Alfa Aesar) were placed in a ceramic crucible that was heated by a tungsten wire filament. A power supply of approximately $100 \mathrm{~W}$ was used for heating the source. This power supply was raised steadily over a period of 5 minutes until a stable deposition rate in the range of $0.6-0.7 \mathrm{~nm} / \mathrm{s}$ was reached. The pressure rose to the mid-range of $10^{-6}$ Torr during film deposition. A shutter blocked CdS flux until the desired deposition rate was reached. This was held for a 2-minute outgassing period and then the shutter was opened and a deposition began. The deposition rate and thickness were measured using a quartz crystal microbalance (QCM). The QCM was calibrated by a cross-sectional SEM image of the CdS film deposited on a silicon wafer. The deposition lasted 5 min that produced a $\sim 200 \mathrm{~nm}$ thick CdS film. At the end of the deposition the sample was covered by the shutter and the deposition power was slowly decreased. The system was then left to cool for an hour before removing the CdS/mica sample. During a deposition, the sample had no intentional heating but the temperature remained at $80 \pm$ $5{ }^{\circ} \mathrm{C}$ range resulted from the radiative heat from the $\mathrm{CdS}$ source. The distance from the CdS source to the mica substrate was about $30 \mathrm{~cm}$.

\section{MOCVD of CdTe on CdS/mica substrates}

An undoped CdTe film was grown using a vertical, cold wall MOCVD system. Before loading the CdS/mica substrate into the chamber, the substrate was blown with dry nitrogen gas to remove any dust particles sitting on the surface. The growth temperature and pressure were $400^{\circ} \mathrm{C}$ and 100 Torr, respectively. Dimethlycadmium (DMCd) and diisopropyltelluride (DIPTe) were used as metalorganic precursors for $\mathrm{Cd}$ and Te, respectively. Hydrogen $\mathrm{H}_{2}$ was used as the carrier gas. The flow rates of $\mathrm{H}_{2}$ through DMCd and DIPTe bubblers were 25 standard cubic centimeters per minute (sccm) and $100 \mathrm{sccm}$, respectively. The $\mathrm{H}_{2}$ flow rate was maintained at 2.2 standard liters per minute (slm). The mole fractions of $\mathrm{Cd}$ and Te were calculated to be $1.2 \times$ $10^{-4}$ and $9 \times 10^{-5}$, respectively. Three sets of $\sim 2 \mu \mathrm{m}$ thick CdTe film on $\sim 200 \mathrm{~nm}$ thick CdS film on mica samples have been prepared and characterized and results are reproducible. One thinner CdTe film of $\sim 500 \mathrm{~nm}$ was grown on $200 \mathrm{~nm}$ thick CdS film on mica to study the effect of CdTe thickness on optical property.

\section{Characterization techniques used}

The surface morphologies of mica, CdS and CdTe films were imaged using an AFM (PSI XE100) in non-contact mode. The AFM tip (HQ: NSC16/Al BS) used has a tip radius of $\sim 8 \mathrm{~nm}$, a force constant of $45 \mathrm{~N} / \mathrm{m}$, and a resonant frequency of $190 \mathrm{kHz}$. RHEED pole figure measures 
the near surface structure and texture while X-ray pole figure measures the average structure and texture of the entire thickness of a film. The RHEED electron gun (model RDA-003G) generated a $20 \mathrm{keV}$ electron beam incident at a glancing angle of $<1^{\circ}$ on the sample surface and the emission current was $41 \mathrm{~mA}$. The RHEED pattern was projected on a phosphor screen mounted on a 6-inch flange in the high vacuum chamber with a base pressure of $10^{-8}$ Torr and was captured by a charge coupled device (CCD) camera positioned outside the chamber.

To characterize samples' crystal structures, both X-ray diffraction (XRD) and TEM diffraction were carried out. XRD spectra were measured by using an X-ray diffractometer (Bruker D8 Discover) with a $\mathrm{Cu} \mathrm{K}$ source of wavelength $\lambda=1.5405 \AA$ and a point detector. The incident beam and detector slits used to achieve the maximum resolution were $0.1 \mathrm{~mm}$ and $0.2 \mathrm{~mm}$, respectively. X-ray pole figures were collected using larger slits, each of width $0.6 \mathrm{~mm}$, to maximize the signal. The X-ray pole figure scan was completed in a continuous scanning mode with $1^{0}$ step sizes in both polar chi $(\chi)$ and azimuthal phi $(\varphi)$ directions, and a $4 \mathrm{~s}$ counting time. The TEM sample protected by a Pt coating was thinned by FIB milling using energetic Ga ${ }^{+}$ions and the in-situ lift-out specimen preparation technique. The thinned sample was mounted on a liquid nitrogen cooled sample stage to minimize the sample's mechanical drifting. A $200 \mathrm{keV}$ electron beam was used to obtain the TEM (JEOL $2100 \mathrm{~F}$ ) bright field images, high resolution images, and electron diffraction patterns. Atomic percentages of the elements in mica, CdS, CdTe and at the interface of mica and CdS as well as the interface of CdS and CdTe of the FIB made samples were determined by energy dispersion spectroscopy (EDS) in the same TEM system.

The steady-state PL and time-resolved PL experiments were conducted at room temperature using a customized time-resolved PL system. A pulsed diode laser (Picoquant) with a wavelength of $405 \mathrm{~nm}$ was used as the excitation source. The pulse width and pulse frequency were $50 \mathrm{ps}$ and $20 \mathrm{MHz}$, respectively. The estimated power density in the area of $1 \mu \mathrm{m}$ laser spot diameter was $\sim 0.3 \mathrm{MW} / \mathrm{cm}^{2}$. The incident laser was directed onto the sample through an inverted microscope (Nikon Eclipse Ti). The PL signal was then directed into a monochromator (Princeton Instruments SP-2358), inside which the grating wavelength was fixed at the PL peak position. The scanning resolution of the monochromator was $0.001 \mathrm{~nm}$ and the slit width was fixed to $<2 \mathrm{~mm}$. A single photon Si detector (Picoquant PDM) was aligned at the exit port of the monochromator to count photons and to collect steady state PL and time resolved PL data with a 0.025 ns time resolution.

The photocurrent of a sample collected at room temperature was excited using a lamp with a variable intensity output from 0 to $30 \mathrm{~mW} / \mathrm{cm}^{2}$. The wavelength spectrum of the lamp ranges from 400 to $1000 \mathrm{~nm}$ with a peak intensity around $650 \mathrm{~nm}$ and a full-width-at-half-maximum of $\sim 200 \mathrm{~nm}$. The photocurrent differs when different excitation wavelength is used. The illumination area on the sample is about $0.10 \pm 0.05 \mathrm{~cm}^{2}$. The source and drain contact electrodes are made of indium dots and the distance between the electrodes is about $0.76 \mathrm{~cm}$. The photocurrent vs. drain-source voltage $\left(I-V_{D S}\right)$ curves under the light illumination and dark conditions are linear indicating good Ohmic contacts. The inverse of the slope from the $I-V_{D S}$ gives the resistance. A mechanical chopper with a variable speed from 0.1 to $23 \mathrm{~Hz}$ was used to turn on and off of the lamp light. An oscilloscope with an internal resistance of $1 \mathrm{M} \Omega$ was used to collect the photocurrent. Any change in the conductivity of the sample results in an increased 
flow of current in the circuit which will increase the potential across the load resistor $R$. This can be detected using the oscilloscope. A $1 \mathrm{M} \Omega$ resistor $R$ comparable to the internal resistance of the oscilloscope was connected in parallel to the oscilloscope. This gives an equivalent resistance of $0.5 \mathrm{M} \Omega$. The measured photocurrent is calculated from the voltage $V$ measured from the oscilloscope divided by $0.5 \times 10^{6} \Omega$. The current measured from CdS is in the hundreds of nA. The currents measured from $\sim 500 \mathrm{~nm}$ and $\sim 2 \mu \mathrm{m}$ thick CdTe on CdS are tens of nA and hundreds of nA, respectively, due to different resistances. We assume that the insulator substrate mica does not contribute to the measured photocurrent.

The Hall mobility measurement was carried out at room temperature using a homemade van der Pauw method with four Indium contact points located near the four corners of the sample. The mobility, carrier type and concentration of the CdS film were measured under a current of 1 and $3 \mathrm{nA}$ and a magnetic field of 0.4000 Tesla. For the CdTe film on CdS the Hall measurement was performed at $1 \mathrm{nA}$ and 0.2000 to 0.4000 Tesla applied magnetic field. At each applied current, the Hall voltage after a time delay was stabilized and recorded. The experiment was repeated multiple times. The current input and voltage output terminals were also reversed to collect the data multiple times. Then an average value with an uncertainty was obtained from all the data collected. 


\section{Results and Discussion}

\section{(a) AFM images of mica, CdS film and CdTe film}

Figures 1(a), (b) and (c) show AFM images collected from the surfaces of cleaved mica (10 $\mu \mathrm{m}$ $\times 10 \mu \mathrm{m})$, CdS film on mica $(2 \mu \mathrm{m} \times 2 \mu \mathrm{m})$, and CdTe film on CdS on mica $(10 \mu \mathrm{m} \times 10 \mu \mathrm{m})$, respectively. The cleaved mica is almost featureless with the vertical depression depth in the sub $\mathrm{nm}$ regime and the opening diameter of the tapered depression of $0.7 \pm 0.1 \mu \mathrm{m}$. The vertical root mean square (RMS) roughness of mica scanned over various areas is $0.16 \pm 0.02 \mathrm{~nm}$ and the lateral correlation length is on the order of several tens of $\mu \mathrm{m}$. These numbers support the high quality of the bare mica surface. The extracted roughness parameters from height-height correlation analysis [38] including vertical RMS roughness $\omega$ and lateral correlation length $\xi$ values of CdS film, $2 \mu \mathrm{m}$ and $500 \mathrm{~nm}$ thick CdTe films are listed in Table 1. The RMS roughness of CdS on mica is small and is presented in section (b). Both RMS roughness and lateral correlation length of CdTe increase one order of magnitude as compared with that of CdS. The $\omega$ and $\xi$ values of CdTe film increase as the film thickness increases. The mica surface is too smooth to perform a height-height correlation analysis. Fig. 1(d) shows a TEM cross-section view of the CdTe/CdS/mica film. The intensity contrast variation in the TEM image is due to the diffraction contrast from grains with small angle grain boundaries. Four distinct regions can be seen, the mica substrate, a $\sim 200 \mathrm{~nm}$ CdS layer, a $\sim 2 \mu \mathrm{m}$ thick CdTe layer, and a Pt coating. The submicrons grain size in the $\sim 2 \mu \mathrm{m}$ thick CdTe film shown in TEM image is in the same order of magnitude as $\xi$ obtained from the AFM image.

Table 1 Roughness parameters extracted from a height-height correlation analysis of AFM images of the mica substrate, CdS, and CdTe films

\begin{tabular}{|l|l|l|l|}
\hline Sample & $\begin{array}{l}\text { Vertical RMS } \\
\omega(\mathrm{nm})\end{array}$ & $\begin{array}{l}\text { Lateral correlation length } \\
\xi(\mathrm{nm})\end{array}$ \\
\hline Mica substrate & $0.16 \pm 0.02$ & --- \\
\hline CdS & $200 \mathrm{~nm}$ & $3.7 \pm 0.3$ & $34.5 \pm 1.7$ \\
\hline \multirow{2}{*}{ CdTe } & $2 \mu \mathrm{m}$ & $125.8 \pm 13.1$ & $671.3 \pm 28.2$ \\
\cline { 2 - 4 } & $500 \mathrm{~nm}$ & $48.5 \pm 5.7$ & $246.1 \pm 7.2$ \\
\hline
\end{tabular}

\section{(b) $X$-ray diffraction, rocking curves, and $X$-ray pole figure of CdS film on mica}

Figure 2(a) shows X-ray theta $(\theta) v s .2$ theta $(2 \theta)$ spectrum of the CdS film on mica presented in the range from 10 to $45^{\circ}$. Strong mica $(00 l)$ peaks for $l=2 n$ with integer $n=1,2,3,4$, 5 , and 6 were observed in the angular range from 5 to $60^{\circ}$. This shows that mica is a good single crystal with the (001) surface orientation. There are no peaks correspond to $l=2 n+1$ because for the out-of-plane c axis, the structure factor from the sum of the scattering from an atom at $x, y$, and $z$ in the first layer and the atom at $x+1 / 2, y+1 / 2, z$ in the layer below gives a zero value. Mica has a monoclinic structure (space group $\mathrm{C} 2 / \mathrm{c}$ and space number 15 ) with the bulk lattice constants $a$ $=5.225 \AA, b=9.163 \AA$, and $c=20.275 \AA, \alpha=\gamma=90^{\circ}, \beta=95.78^{\circ}$. The interplanar spacing $d_{h k l}$ for the $(h k l)$ planes is $d_{h k l}=\left\{\frac{1}{\sin ^{2} \beta}\left(\frac{h^{2}}{a^{2}}+\frac{k^{2} \sin ^{2} \beta}{b^{2}}+\frac{l^{2}}{c^{2}}-\frac{2 h l \cos \beta}{a c}\right)\right\}^{-1 / 2}$. The measured peak position for mica (006) is at $2 \theta=26.91^{\circ} \pm 0.01^{\circ}$ (theory $26.499^{\circ}$ ) and the lattice constant 
ccalculated from this $2 \theta$ peak is $19.965 \AA$. The lattice constant c averaged from six measured mica peaks (00l), where $l=2,4,6,8,10$ and 12 is $20.055 \pm 0.049^{\circ} \AA$, slightly lower than the bulk lattice constant $c=20.275 \AA$ A.

The CdS (0002) X-ray diffraction peak was observed at $2 \theta=26.63^{\circ} \pm 0.01^{\circ}$ (theory $26.587^{\circ}$ ) and it is very close to the mica (006) peak measured at $2 \theta=26.91^{\circ} \pm 0.01^{\circ}$ [39]. The inset of Fig. 2(a) shows the magnified CdS (0002) peak near the high intensity mica (006) peak. CdS has a hexagonal crystal structure (space group $\mathrm{P}_{3} \mathrm{mc}$ and space number 186). The bulk lattice constants are $a=b=4.142 \AA, c=6.724 \AA, \alpha=\beta=90.0^{\circ}$, and $\gamma=120.0^{\circ}$. Although the intensity of CdS (0002) peak is much lower than that of mica (006) peak, the CdS peak intensity count is still appreciable. This allows the determination of the FWHMs of the CdS (0006) and mica (006) to be $0.13 \pm 0.01^{\circ}$ and $0.03 \pm 0.01^{\circ}$, respectively. Using Scherrer formula, the lower limit of the average vertical coherent size in the CdS film is $63.78 \pm 4.61 \mathrm{~nm}$ (underestimated because no decovolution of instrument response function). This size is smaller than the $200 \mathrm{~nm}$ CdS film thickness and is reasonable. The FWHM of $0.03 \pm 0.01^{\circ}$ associated with mica (006) is close to the instrument resolution limit and the mica's average coherent crystalline size is extremely large as expected for a single crystal. X-ray rocking curves were measured from the mica (006) and CdS (0002) peaks and their FWHMs are $\sim 0.3^{\circ}$ and $\sim 2.4^{\circ}$, respectively. These FWHMs of rocking curves indicate that the surface planes of mica do not deviate too much from the mica(001) orientation. Similarly it is true for the CdS(0001) orientation.

In order to determine the in-plane epitaxy, the X-ray pole figure of mica was collected. Mica (001) pole figure has a center pole only at $\chi=0^{\circ}$ that does not help the determination of the inplane epitaxy relationship of a film grown on top of it. But for the $\{111\}$ pole figure, it has poles at $\chi \neq 0^{\circ}$. Figure 3(a) shows four asymmetric poles. The theoretically calculated $\{111\}$ poles for $d_{111}=4.33 \AA$ and $2 \theta=20.49^{\circ}$ are (111), $(1 \overline{1} 1),(\overline{111})$ and $(\overline{1} 1 \overline{1})$ at $\chi=72.7^{\circ}$. Note that $(\overline{111})$ and $(\overline{1} 1 \overline{1})$ are overlapping with (111) and (1 $\overline{1} 1)$, respectively. Therefore, only two poles were observed as seen in Fig. 3(a). Other $(h k l)$ of $\{111\}$ such as $(1 \overline{11}),(\overline{1} 11),(11 \overline{1})$, and $(\overline{1} 11)$ have different $d$ spacing of $4.50 \AA$ and the $2 \theta$ value $=19.73^{\circ}$. They were not detected when $2 \theta$ was set at $20.49^{\circ}$. The remaining two poles were determined to be $(021)$ and $(0 \overline{2} 1)$. The theoretical $2 \theta$ values for these two poles are $19.85^{\circ}$ that are very close to $20.49^{\circ}$ set for mica $\{111\}$ poles and therefore these two poles were detected as seen in Fig. 3(a). The average FWHMs of the mica $\{111\}$ and mica $\{021\}$ poles along the azimuthal and chi directions are $1.0^{\circ} \pm 0.5^{\circ}$ and $5.1^{\circ} \pm$ $0.5^{\circ}$, respectively. See Table 2 . The $\chi$ angle for $(021)$ and $(0 \overline{2} 1)$ is $77.2^{\circ}$. This $\chi$ angle differs from $\chi=72.7^{\circ}$ for the $(111)$ and $(1 \overline{1} 1)$ poles. Note that $(0 \overline{21})$ and $(02 \overline{1})$ overlap with $(021)$ and $(0 \overline{2} 1)$ and did not appear as separate poles. The theoretical phi angle between (111) and (1 $\overline{1} 1)$ poles is not $60^{\circ}$ but $59.4^{\circ}$ because $\beta$ angle is not $90^{\circ}$ but $95.78^{\circ}$. For the same reason the $\phi$ angle between (111) and (021) poles is not $60^{\circ}$ but $60.3^{\circ}$. The in-plane directions used are labeled as [010] and [100]. Note that for mica, the c-axis or [001] direction has a non- $90^{\circ}$ or $95.78^{\circ}$ angle with respect to the (001) plane.

Without moving the sample position after the measurement of the mica pole figure, the CdS $\{01 \overline{1} 1\}$ pole figure was collected and is shown in Fig. 3(b). The $d_{01 \overline{1} 1}$ spacing for $\{01 \overline{1} 1\}$ is $3.17 \AA$ and the calculated $2 \theta$ angle is $28.17^{\circ}$. Experimentally the $2 \theta$ angle was set at $28.40^{\circ}$ for 
pole figure measurement. Six poles each at $\chi=61.9^{\circ}$ with $60^{\circ}$ azimuthal angular separation were

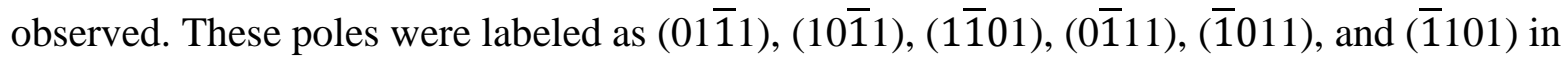
Fig. 3(b). There are six more poles but they overlap with the labeled ones. The average FWHMs $\Delta \phi$ and $\Delta \chi$ of the CdS $\{01 \overline{1} 1\}$ poles along the $\phi$ and $\chi$ directions are $10.6^{\circ} \pm 0.5^{\circ}$ and $4.3^{\circ} \pm 0.5^{\circ}$, respectively. See Table 2.

The $\{01 \overline{1} 1\}$ pole data collected from the CdS film shown in Figure 3(b) has additional poles from mica. For example, the mica (114) pole at $\chi=45.4^{\circ}$ is aligned with the $\mathrm{CdS}(01 \overline{1} 1)$ pole at $\chi$ $=61.9^{\circ}$ at the azimuthal angle of $60^{\circ}$. The $d$ spacing for mica (114) pole is $3.23 \AA$ and the calculated $2 \theta=27.60^{\circ}$. This $2 \theta$ angle is close to the $2 \theta$ angle experimentally set at $28.40^{\circ}$ for the CdS $\{01 \overline{1} 1\}$ pole figure measurement. Therefore, the intensity of the mica (114) pole was picked up in the pole figure measurement. One mica (1 14 ) pole was also picked up. Similarly, the intensity of the mica (115) pole corresponding to $d=2.88 \AA, 2 \theta=30.95^{\circ}$ and $\chi=39.5^{\circ}$ was also picked up, although the intensity is weaker than that of the mica (114) pole. Three other (1 $\overline{1} 5)$, (115), and (115) poles were also labeled.

Figure 3(b) shows that four out of six CdS poles are aligned with four mica poles in certain azimuthal angles. For example, the CdS $(01 \overline{1} 1)$ pole is aligned with the mica (111) pole at $60^{\circ}$ azimuthal angle. From this alignment one can determine the in-plane epitaxial relationship, $[\overline{1} 100]_{\mathrm{CdS}} / /[010]_{\text {mica. }}$. The fact that CdS film can grow on the mica substrate epitaxially despite a large lattice mismatch supports the van der Waals epitaxy.

Table 2 FWHMs $\Delta \phi$ and $\Delta \chi$ along azimuthal $\phi$ and $\chi$ directions measured from the XRD and RHEED pole figures of mica(001), CdS(0001), and CdTe(111) films.

\begin{tabular}{|c|c|c|c|c|c|c|c|}
\hline \multirow{2}{*}{$\begin{array}{l}\text { Pole } \\
\text { figure }\end{array}$} & \multirow{2}{*}{$\begin{array}{l}\text { Direc } \\
\text {-tion }\end{array}$} & \multicolumn{2}{|l|}{ Mica } & \multicolumn{2}{|l|}{$\mathrm{CdS}$} & \multicolumn{2}{|l|}{ CdTe } \\
\hline & & Pole & FWHM & Pole & FWHM & Pole & FWHM \\
\hline \multirow[t]{2}{*}{ X-ray } & $\Delta \phi$ & $\begin{array}{l}\{021\} \\
\&\{111\}\end{array}$ & $\begin{array}{l}1.0 \pm 0.5^{\circ} \\
1.0 \pm 0.5^{\circ}\end{array}$ & $\{01 \overline{1} 1\}$ & $10.6 \pm 0.5^{\circ}$ & $\{1 \overline{1} 1\}$ & $\begin{array}{l}10.8 \pm 0.5^{\circ}(2 \mu \mathrm{m}) \\
8.7 \pm 0.5^{\circ}(500 \mathrm{~nm})\end{array}$ \\
\hline & $\Delta \chi$ & $\begin{array}{l}\{021\} \\
\&\{111\}\end{array}$ & $\begin{array}{l}4.4 \pm 0.5^{\circ} \\
5.1 \pm 0.5^{\circ}\end{array}$ & $\{01 \overline{1} 1\}$ & $4.3 \pm 0.5^{\circ}$ & $\{1 \overline{1} 1\}$ & $\begin{array}{l}5.9 \pm 0.5^{\circ}(2 \mu \mathrm{m}) \\
4.6 \pm 0.5^{\circ}(500 \mathrm{~nm})\end{array}$ \\
\hline \multirow[t]{2}{*}{ RHEED } & $\Delta \phi$ & \multicolumn{2}{|c|}{ Instrument limit } & $\{01 \overline{1} 3\}$ & $10.8 \pm 1.1^{\circ}$ & $\begin{array}{l}\{224\} \\
\{113\}\end{array}$ & $\begin{array}{l}2.7 \pm 0.9^{\circ}(2 \mu \mathrm{m}) \\
11.2 \pm 1.7^{\circ}(500 \mathrm{~nm}) \\
2.8 \pm 0.9^{\circ} \quad(2 \mu \mathrm{m}) \\
10.9 \pm 1.6^{\circ}(500 \mathrm{~nm})\end{array}$ \\
\hline & $\Delta \chi$ & \multicolumn{2}{|c|}{ Instrument limit } & $\{01 \overline{1} 3\}$ & $5.3 \pm 1.1^{\circ}$ & $\begin{array}{l}\{224\} \\
\{113\}\end{array}$ & $\begin{array}{l}4.1 \pm 0.5^{\circ}(2 \mu \mathrm{m}) \\
4.4 \pm 0.7^{\circ}(500 \mathrm{~nm}) \\
5.2 \pm 1.5^{\circ}(2 \mu \mathrm{m}) \\
5.1 \pm 1.3^{\circ}(500 \mathrm{~nm})\end{array}$ \\
\hline
\end{tabular}




\section{(c) X-ray diffraction, rocking curves, and $X$-ray pole figure of $C d T e / C d S$ on mica}

Figure 2(b) shows the X-ray $\theta v s$. $2 \theta$ spectrum of the CdTe film on CdS/mica plotted in normal scale. A strong $\mathrm{CdTe}(111)$ peak at $2 \theta=23.8^{\circ}$ was observed. Other peaks from mica (004), mica (006), and mica (008) were labeled. This $2 \theta=23.8^{\circ}$ angle corresponds to a d-spacing of $3.24 \AA$ which is consistent with the $\mathrm{CdTe}(111)$ orientation of the CdTe cubic structure (space group F $\overline{4} 3 \mathrm{~m}$, space number 216) with $a=b=c=6.481 \AA$, and $\alpha=\beta=\gamma=90^{\circ}$ ). The FWHM of the rocking curve measured from the CdTe film is $\sim 2.6^{\circ}$. Recall that the FWHMs measured from mica and CdS are $0.3^{\circ}$ and $2.4^{\circ}$, respectively. Literature reports that the FWHM of rocking curve of $\mathrm{CdTe}(001)$ film grown by close space sublimation on $6^{\circ}$ mis-oriented $\mathrm{Ge}(001)$ substrate decreases as the film thickness increases. For a $2 \mu \mathrm{m}$ thick CdTe film on Ge(001) the rocking curve is $\sim 0.3^{0}[5]$. Our $2.6^{\circ}$ is from CdTe(111) film on epitaxial CdS(0001) film that is much broader than $0.3^{\circ}$ but the rocking curve spread could be reduced by growing a thicker CdTe film.

Figure 3(c) shows the X-ray pole figure of the cubic $\mathrm{CdTe}(111)$ orientation. The $2 \theta$ was experimentally set at $23.74^{\circ}$ for the $\{111\}$ pole measurement. Six intense poles with $60^{\circ}$ azimuthal angle apart were observed at $\chi=70.5^{\circ}$. Theoretically the CdTe(111) pole figure has a total of four poles, three poles at $\chi=70.5^{\circ}$ with $120^{\circ}$ azimuthal angle apart plus one at the center $\chi=0^{\circ}$. The fact that there are six poles at $\chi=70.5^{\circ}$ implies there exists a $2^{\text {nd }}$ set of orientation domain that is twin of the $1^{\text {st }}$ set of orientation domain. The average FWHMs of the CdTe $\{1 \overline{1} 1\}$ poles along the azimuthal and chi directions are $10.8^{\circ} \pm 0.5^{\circ}$ and $5.9^{\circ} \pm 0.5^{\circ}$, respectively. See Table 2.

From the X-ray pole figure of the CdTe film shown in Fig. 3(c) we concluded that the CdTe film forms epitaxially on the CdS film. We learned that the epitaxy relationship between CdS and mica is $[\overline{1} 100]_{\mathrm{CdS}} / /[010]_{\text {mica }}$ from Fig. 3(b) and the previous discussions. Under the same sample position while taking the X-ray $\{111\}$ pole figure of the CdTe film on CdS, the mica $\{111\}$ poles were collected. Judging from the relative pole positions of CdTe in Fig. 3(c) and mica in Fig. $3(a)$ it is concluded that the CdTe $(11 \overline{1})$ pole aligns with the mica (111) pole at the same $60^{\circ}$ azimuthal direction. This means $[\overline{1} 2 \overline{1}]_{\mathrm{CdTe}} / /[010]_{\text {mica }}$. Using mica $[010]_{\text {mica }}$ as the common reference, the epitaxial relationship between CdTe and CdS is determined to be parallel epitaxy, $[\overline{1} 2 \overline{1}]_{\mathrm{CdTe}} / /[\overline{1} 100]_{\mathrm{Cds}}$. Because there are six equivalent in-plane directions for every $60^{\circ}$ in hexagon $\mathrm{CdS}(0001)$ and sphalerite lattice $\mathrm{CdTe}(111)$, one can also write the epitaxy as any one of the six equivalent directions, for example, $[11 \overline{2}]_{\mathrm{CdTe}} /[01 \overline{1} 0]_{\mathrm{Cds}}$.

Yan et. al. reported the growth of CdTe on a hexagonal CdS single crystal substrate by closespaced sublimation (CSS)[12]. Their TEM shows (111) CdTe $/ /(0001)_{\mathrm{Cds}}$ and $[110]_{\mathrm{CdTe}} / /[11 \overline{2} 0]_{\mathrm{CdS}}$ for the out-of-plane orientation and in-plane alignment, respectively. Their out-of-plane orientation is the same as ours, whereas our in-plane relationship is $[\overline{1} 2 \overline{1}]_{\mathrm{CdTe}} / /[\overline{1} 100]_{\mathrm{Cds}}$. Their much higher growth rate of $1 \mu \mathrm{m} / \mathrm{min}$ using CSS method compared with our MOCVD method may contribute to this difference.

When the growth sequence is reversed, i.e., CdS grown on CdTe, the same interface epitaxial relationship was reported in the literature. For example, from the growth of CdS film on $\mathrm{CdTe}(111)$ by molecular beam epitaxy, the same in-plane $[11 \overline{2}]_{\mathrm{CdTe}} / /[01 \overline{1} 0]_{\mathrm{Cds}}$ and the same out- 
of-plane $[111]_{\mathrm{CdTe}} / /[0001]_{\mathrm{Cds}}$ epitaxy relationships were observed[40]. Another example is the low energy electron diffraction (LEED) patterns of the CdS film grown on a single crystal $\mathrm{CdTe}(111)$ substrate which show a six-fold symmetry similar to our X-ray pole figure results[41].

\section{(d) RHEED surface pole figures of CdS film and CdTe film CdS film on mica}

$\mathrm{X}$-ray pole figure measurement and analysis provide the structure and epitaxial relationship between the CdS film and mica substrate. RHEED pole figure measurement and analysis using the transmission mode of RHEED provide the structure and texture near the surface within the probing depth of electrons[42, 43], typically on the order of $10 \mathrm{~nm}$ for $15 \mathrm{keV}$ electron energy[44]. Fig. 4(a) shows a RHEED pattern collected from the CdS film using a $15 \mathrm{keV}$ primary electron beam energy incident at azimuthal angle $\phi=63^{\circ}$. The pattern consists broad diffraction spots and arcs. The arcs represent a well-developed texture.The patterns collected from other azimuthal angles show similar structures. The scale bar in the reciprocal space was calibrated from an epitaxial CdTe(100) film on a single crystal GaAs(100) [8]. A radial scan (white dashed line) perpendicular to the shadowing edge (white dashed line) is shown in Fig. 4(a). The reciprocal distance of the diffraction spots ( $h k i l)$ of the CdS film were measured using the calibration scale bar. The real space interlayer spacings $d_{h k i l}$ calculated from the measured reciprocal distances were consistent with the theoretical spacing using the bulk lattice constants of CdS. From the comparison of the measured $d_{h k i l}$ spacings and the expected theoretical values, the ( $h k i l)$ are determined to be (0002), (0004), and (0006) within the experimental uncertainty of sub angstroms. This shows that the out-of-plane direction is the same [0001] direction as that determined from XRD.

Figure 4(b) shows the RHEED pole figure constructed from the CdS $\{01 \overline{1} 3\}$ diffraction spots. There are six poles and the average FWHMs $\Delta \phi$ and $\Delta \chi$ of all six poles are $\sim 10.8 \pm 1.1^{\circ}$ and $\sim .3$ $\pm 1.1^{\circ}$ along the $\phi$ and $\chi$ directions, respectively. See Table 2 . These numbers are larger than the RHEED instrument response function of $\sim 4^{\circ}[8,44]$. Both are also larger than thatof the X-ray pole figure of the CdS film presented in Fig. 3(b). This implies that near surface in-plane texture may not be as good as the average texture of the CdS film.

Epitaxial CdS films on van der Waals substrates were reported in the literature. For examples, CdS thin films can be grown on mica at near room temperature [39] or by co-evaporation of CdS powders and sulfur on mica held between $430-800^{\circ} \mathrm{C}$. The RHEED pattern of the film shows diffraction spots. However, based on one pattern only the out-of-plane orientation [0001] was determined but not the in-plane alignment direction relative to mica[36]. For vacuum evaporation of CdS powders on mica substrate held at room temperature, the epitaxial relationships determined by RHEED were CdS(0001)//mica(0001) and $[10 \overline{1} 0]_{\text {cds }} / /[10 \overline{1} 0]_{\text {mica }}$ for the out-of-plane orientation and in-plane direction alignments, respectively[35]. Their out-ofplane direction and in-plane direction alignments are the same as ours. For CdS nanostructures on mica, vertically aligned nanowire array was grown on mica(001) using chemical vapor transport method at $750^{\circ} \mathrm{C}$. The growth direction or out-of-plane direction of individual CdS nanowire was determined by TEM images to be in the [0001] direction[31]. However, only the individual CdS nanorod was examined by TEM, the in-plane alignment was not determined 
experimentally. The in-plane alignment was assumed to be $[11 \overline{2} 0]_{\mathrm{Cds}} / /[100]_{\text {mica }}$ using the criterion that lattice mismatch was the smallest along these two directions at the interface.

\section{CdTe film on CdS film on mica}

Fig. 4(c) shows a RHEED pattern collected from the CdTe film using a $20 \mathrm{keV}$ primary electron beam energy incident at the azimuthal angle $\phi=0^{\circ}$. The pattern consists diffraction spots, a sign of transmission mode of RHEED from near surface of the CdTe film[44]. The patterns collected from every other $60^{\circ}$ azimuthal angles show similar patterns. From the measured reciprocal spacings of these $(\mathrm{hkl})$ spots outlined by a white dashed line and compared their values with the expected theoretical reciprocal spacings, the specific $(h k l)$ are labeled. Figure 4(d) shows the RHEED CdTe $\{224\}$ pole figure. The RHEED pole figure of near surface CdTe looks similar to the X-ray CdTe pole presented in Fig. 3(c). There are two orientation domains, three primary $\{224\}$ poles and three twin poles of $\{224\}$ labeled as " $T$ " in front of pole labels. All six poles have an average $\chi$ angle located at $\sim 20 \pm 1^{\circ}$. The theoretical $\chi$ angle is $19.5^{\circ}$.

The measured FWHMs of $\Delta \phi$ and $\Delta \chi$ from RHEED pole figure of the $2 \mu \mathrm{m}$ and $500 \mathrm{~nm}$ thick CdTe films are listed in Table 2. The measured FWHMs of the CdTe $\{224\}$ poles in the azimuthal direction are narrow and an average $\Delta \phi$ of FWHMs from the six $\{224\}$ poles is $=2.7 \pm$ $0.9^{\circ}$. A similar analysis of the $\{113\}$ poles gives $\Delta \phi=2.8 \pm 0.8^{\circ}$. The average $\Delta \chi$ of FWHMs from the six $\{224\}$ poles is $=4.1 \pm 0.5^{\circ}$. Both RHEED $\{224\}$ pole figure shown in Fig. 4(d) and RHEED $\{113\}$ pole figure (not shown here) indicate a better quality compared with the RHEED $\{01 \overline{1} 3\}$ pole figure of CdS shown in Fig. 4(b). Recall that for CdS film, $\Delta \phi=10.8 \pm 1.1^{\circ}$ and $\Delta \chi$ $=5.3 \pm 1.1^{\circ}$. The growth temperature of CdTe was $400^{\circ} \mathrm{C}$. At this temperature the CdS film was effectively annealed to form a high quality single crystal epitaxial film. As we shall see later, an interface alloying also occurs under this growth temperature. The alloying created a gradual change in the lattice constant at the interface and reduces the lattice mismatch between CdTe and CdS.

In Table 2 we list the FWHMs measured from RHEED pole figures. We observed the texture spread $\Delta \phi$ of the $200 \mathrm{~nm}$ thick CdS near surface is about the same as that from the average of the entire CdS film thickness from the X-ray pole figure. For the $2 \mu \mathrm{m}$ thick CdTe film the texture spread $\Delta \phi\left(=2.7^{\circ}\right)$ near surface is less than that $\left(10.8^{\circ}\right)$ from the average of the entire CdTe film thickness. However, for the $500 \mathrm{~nm}$ thick CdTe film the results are similar within experimental uncertainty. This may be related to the range of $S$ diffusion $(250 \mathrm{~nm})$ into the CdTe film measured by EDS presented later in the TEM section. For the $2 \mu \mathrm{m}$ thick CdTe film, most part of the CdTe film has no S except within 250 nm of the CdS and CdTe interface. But for the 500 $\mathrm{nm}$ thick CdTe film the percentage of CdTe that contains diffused S and therefore the alloying of CdS and CdTe is high. The alloying may introduce more defects in the CdTe film.

The average of the measured FWHMs from the six CdTe $\{224\}$ poles along the $\chi$ direction from the $2 \mu \mathrm{m}$ CdTe film is $\Delta \chi_{\{224\}}=4.1 \pm 0.5^{\circ}$. We have also analyzed the six $\{113\}$ poles but the pole figure is not presented here. The average of the measured FWHMs from the six $\{113\}$ poles along the $\chi$ direction is $\Delta \chi_{\{113\}}=5.2 \pm 1.5^{\circ}$. The reason that $\Delta \chi_{\{224\}}<\Delta \chi_{\{113\}}$ is because for a finite electron transmission length $\mathrm{L}$ near the surface, the relationship between the broadening $\Delta \chi_{\{h k l\}}$ of a $\{h k l\}$ spot in the $\chi$ direction is $2 \pi / L=2 \pi / d_{\{h k l\}} \times \Delta \chi_{\{h k l\}}$ where $2 \pi / d_{\{h k l\}}$ is the distance 
of a $(h \mathrm{kl})$ spot from the $(000)$ spot in the reciprocal space and $\mathrm{d}$ is the inter planar spacing of a ( $h k l$ ) diffraction spot in real space. That is $\Delta \chi_{\{h k l\}}=d_{\{h k l\}} / L$. For a fixed incident electron beam energy the $L$ is the same for $\{224\}$ and $\{131\}$ spots and because $d_{\{224\}}=1.32 \AA<d_{\{113\}}=1.95 \AA$, therefore $\Delta \chi_{\{224\}}<\Delta \chi_{\{113\}}$. If the measured $\Delta \chi_{\{h k l\}}$ from the CdTe film on CdS filmis compared with the instrument response function obtained from the CdTe film grown on a single crystal GaAs(100) substrate[8], the values of $\Delta \chi_{\{h k\}}$ is about 0.5 to $1^{\circ}$ larger. This is reasonable considering the CdS film is an epitaxial film and not a single crystal GaAs(100) substrate.

It is interesting to note that if the growth sequence is reversed, i.e., CdS film grown by vacuum deposition on single crystal CdTe(111) substrate, the epitaxial relationship at the interface is similar to that of our CdTe on CdS [45]. The out-of-plane epitaxy is CdS(0001)//CdTe(111). The in-plane epitaxy $[10 \overline{1} 0]_{\mathrm{CdS}} / /[011]_{\mathrm{CdTe}}$ is equivalent to our $[\overline{1} 100]_{\mathrm{CdS}} / /[\overline{1} 2 \overline{1}]_{\mathrm{CdTe}}$ considering the six-fold symmetry in the hexagonal CdS. This is because both CdS(0001) and CdTe(111) have the close-packed planes at the interface.

\section{(e) TEM}

High resolution TEM images and selective area diffraction patterns (SADP) were collected from cross section of mica substrate, interface of mica and CdS, and interface of CdS and CdTe from $2 \mu \mathrm{m}$ thick/CdS/mica and $500 \mathrm{~nm}$ thick CdTe/CdS/mica samples. The out-of-plane orientations for mica, CdS and CdTe are (001), (0001) and (111), respectively. These are consistent with that obtained from X-ray pole figures. TEM SADP and image were also collected from a large grain in CdTe film shown in Figs. 5(a) and 5(b).

The symmetry of the TEM diffraction pattern shown in Fig. 5(a) is consistent with thesphalerite lattice structure viewed along the $[01 \overline{1}]$ zone axis direction. The unit mesh connecting the lowindex spots $000,111,1 \overline{1} \overline{1}$, and 200 is indicated by yellow dashed lines. The ratio of the reciprocal vectors $g(200)$ to $g(111)$ can be estimated from the ratio of the measured reciprocal length $g(200)$ from 000 to 200 to the measured reciprocal length $g(111)$ from 000 to 111 . The experimental determined $g(200) / g(111)$ ratio is 1.181 which is consistent with 1.155 , theoretical ratio of thesphalerite lattice along the $[01 \overline{1}]$ zone axis.

The conversion of the reciprocal spacings $g(200)$ and $g(111)$ to real-space interplanar spacings gives $d_{200}=0.320 \pm 0.005 \mathrm{~nm}$ and $d_{111}=0.370 \pm 0.005 \mathrm{~nm}$, respectively. Within the accuracy in measuring the reciprocal length, these $\mathrm{d}$ spacing values are also consistent with the theoretical real space interplanar spacing $d_{200}=0.324 \mathrm{~nm}$ and $d_{111}=0.374 \mathrm{~nm}$ using the lattice constant of $0.6481 \mathrm{~nm}$. The mirror axis for twins is indicated as the blue solid line. The diffraction pattern also shows twin spots that are indexed in red. The observed twin spots in the TEM diffraction pattern is consistent with the twin poles observed in both the X-ray pole figure shown in Figs. 3(c) and RHEED pole figure shown in 4(d).

The existence of twins can be seen in real space high resolution image shown in Fig. 5(b), where single crystal grains are clearly seen. A twin boundary separating twinned grains is seen. The measured interlayer spacing $d_{111}=0.376 \pm 0.006 \mathrm{~nm}$ is consistent with calculated theoretical $d_{111}$ $=0.374$ within the uncertainty of measuring the length. Low density defects including single stacking faults and multiple stacking faults are seen from other high-resolution TEM images and are not shown here. 
The EDS line profile perpendicular to the interfaces was collected from 20 points covering $~ 700$ nm. The adjacent points are $~ 35 \mathrm{~nm}$ apart. Fig. 5(c) is a plot of S, Cd, Te, and Si atomic percentages (converted from the measured weight percentages). The data (points) start from the mica substrate, then continue to the interface of mica and CdS film, CdS, the interface of CdS and CdTe, and end in the CdTe film. Mica contains Si, O, Al and K and only Si is plotted. The line profiles of S, Cd, and Te are not sharp at interfaces but gradual indicating interdiffusion. S diffuses into mica and CdTe for $\sim 250 \mathrm{~nm}$. Te diffuses into CdS for $200 \mathrm{~nm}$. However, at the right end of the line profiles that is $\sim 250 \mathrm{~nm}$ away from the interface of CdS and CdTe the ratio of Cd to Te is 1 , the right stoichiometry, although the absolute atomic percentage of either Cd or Te is not $50 \%$ due to a non-zero percentage of oxygen. This means for the MOCVD growth condition that we used the CdTe film on CdS film has to be thicker than few hundreds nm thick to achieve good stoichiometry.

This epitaxy across the interface was observed at different regions of CdTe/CdS interface by high resolution TEM[12]. Here the perfect epitaxy at the interface is an alloyed CdTe $\mathrm{C}_{1-\mathrm{x}} \mathrm{S}_{\mathrm{x}}$ with reduced lattice constant or an alloyed $\mathrm{CdS}_{1-x} \mathrm{Te}_{x}$ with increased lattice constant that reduces the original lattice mismatch between the pure CdTe and pure CdS phases. The secondary ion mass spectroscopy and X-ray photoelectron spectroscopy depth profiles also indicate an intermixing at the interface of CdS and CdTe[40]. In reality, in some regions of the CdTe/CdS interface, mismatch dislocations and step dislocations (an extra plane lying at the interface) were observed[12]. The observed distance between the mismatched dislocations at the interface is not a constant, but varies between 10 to 12 times of lattice constant $a$ of CdS.

\section{(f) Steady State PL and time resolved PL CdS film}

The PL is a result from photon absorption/emission from various electronic energy levels in a film. The PL peak in a spectrum provides information on the optical bandgap as well as the crystalline quality and the possible existence of defect states of the film. The time resolved PL decay shape contains information related to minority carrier life time[46]. Figure 6(a) shows the PL spectrum measured from the CdS film at room temperature. There is a single PL peak at 518 $\mathrm{nm}(2.39 \mathrm{eV})$ with a FWHM of $26 \mathrm{~nm}$. As a comparison, a reference PL spectrum from a commercial single crystal CdS (MTI Inc.) has one narrow peak at $519 \mathrm{~nm}(2.389 \mathrm{eV})$ with a FWHM $\sim 15 \mathrm{~nm}$. The single and narrow peak in our epitaxial CdS film indicating a quality film. The PL peak position of the CdS film reported in the literature varies over a wide range from 1.59 to $2.54 \mathrm{eV}$ depending on the growth technique (that could introduce impurities or different microstructures), annealing gas and temperature, $\mathrm{CdCl}_{2}$ treatment temperature[47]. Our as grown epitaxial CdS film without intentional heating during growth has a peak at $2.39 \mathrm{eV}$ that is consistent with their green band $(2.18-2.54 \mathrm{eV})$ after high temperature $\mathrm{N}_{2}$ annealing or high temperature $\mathrm{CdCl}_{2}$ treatment. Figure 6(b) shows the time resolved PL spectrum measured at room temperature from the peak at $518 \mathrm{~nm}$. A single component fit A exp $(-t / \tau)$ of the TRPL curve gives a decay time $\tau=0.14 \pm 0.02 \mathrm{~ns}$.

Table 3 Measured PL peak position and FWHM of $200 \mathrm{~nm}$ CdS film, $2 \mu \mathrm{m}$ CdTe and $500 \mathrm{~nm}$ CdTe films and extracted decay constants from time resolved PL. 


\begin{tabular}{|l|l|l|l|l|l|}
\hline Sample & PL peak $(\mathrm{nm})$ & PL FWHM $(\mathrm{nm})$ & PL peak $(\mathrm{eV})$ & TRPL $\tau_{1}(\mathrm{~ns})$ & TRPL $\tau_{2}(\mathrm{~ns})$ \\
\hline $\begin{array}{l}\mathrm{CdS} \\
200 \mathrm{~nm}\end{array}$ & $518 \pm 0.05$ & $25.69 \pm 0.05$ & 2.39 & \multicolumn{2}{|c|}{$0.14 \pm 0.02$} \\
\hline $\begin{array}{l}\mathrm{CdTe} \\
2 \mu \mathrm{m}\end{array}$ & $814.99 \pm 0.19$ & $66.65 \pm 0.12$ & 1.52 & $0.05 \pm 0.02$ & $0.27 \pm 0.02$ \\
\cline { 2 - 6 } & $842.67 \pm 0.05$ & $20.49 \pm 0.05$ & 1.47 & $0.04 \pm 0.02$ & $0.52 \pm 0.02$ \\
\hline $\begin{array}{l}\mathrm{CdTe} \\
500 \mathrm{~nm}\end{array}$ & $814.29 \pm 0.07$ & $52.75 \pm 0.31$ & 1.52 & $0.05 \pm 0.02$ & $0.27 \pm 0.02$ \\
\cline { 2 - 6 } & $749.71 \pm 0.31$ & $123.67 \pm 0.31$ & 1.65 & $0.04 \pm 0.02$ & $0.23 \pm 0.02$ \\
\hline
\end{tabular}

\section{CdTe film on CdS film}

Figure 6(c) shows the CdTe's PL spectrum measured from the $2 \mu \mathrm{m}$ thick CdTe film at room temperature. There are two PL peaks observed, one at $815 \mathrm{~nm}(1.52 \mathrm{eV})$ with a FWHM of 66 $\mathrm{nm}$ and the other one at $842 \mathrm{~nm}(1.47 \mathrm{eV})$ with a FWHM of $20 \mathrm{~nm}$. Our measured $1.52 \mathrm{eV} \mathrm{PL}$ peak compares well with the measured bandgap of $1.50 \mathrm{eV}$ from the CdTe film grown on CdS on glass by close space sublimation method[7, 48]. Literature reports of the PL of crystalline CdTe nanostructures measured at room temperature is $\sim 1.50-1.51 \mathrm{eV}$ and the FWHM ranges from 25 to $70 \mathrm{~nm}$ [49-51]. The PL of bulk CdTe crystals measured at $4.25 \mathrm{~K}$ is $1.59 \mathrm{eV}$ [52-54]. Our PL data is consistent with crystalline structure measured at room temperature.Our measured $1.47 \mathrm{eV}$ PL peak is attributed to an interface diffusion and reaction that form an alloy of $\mathrm{CdTe}_{1-x} \mathrm{~S}_{x}$ where $x$ is about $0.05[48,55]$. This alloying at the interface is also consistent with the TEM observation

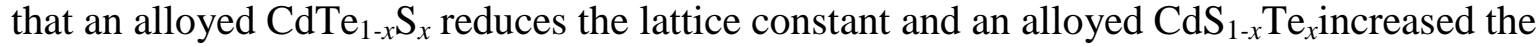
lattice constant in some regions at the $\mathrm{CdTe} / \mathrm{CdS}$ interface[12]. It is also consistent with SIM and XPS [40] and AES [55] characterization of the CdTe/CdS interface. The alloying will reduce the amount of original lattice mismatch between CdTe and CdS. The bandgap of the CdTe $\mathrm{C}_{1-x} \mathrm{~S}_{x}$ alloy where $x$ is about 0.05 , reduces from $1.50 \mathrm{eV}$ to $\sim 1.47 \mathrm{eV}$ as measured by optical absorption[56, 57]. The kinetics of phase separation of CdTe and CdS at $400^{\circ} \mathrm{C}$ growth temperature is slow and $30 \mathrm{~min}$ is not sufficient for complete phase separation to occur. The interface of CdTe and CdS will form a continuous range of composition in solid solution.

As shown in Figure 6(d), the TRPL study of the peak at $1.52 \mathrm{eV}$ or $815 \mathrm{~nm}$ indicates that there are two decay components for $2 \mu \mathrm{m}$ thick CdTe, a fast decay $\tau_{1}$ and a slow decay $\tau_{2}$. Using two decay functions fit [A exp $\left.\left(-t / \tau_{1}\right)+B \exp \left(-t / \tau_{2}\right)\right]$, we obtained $\tau_{1}=0.05 \pm 0.02 \mathrm{~ns}$ and $\tau_{2}=0.27 \pm$ $0.02 \mathrm{~ns}$ for the lifetime associated with surface recombination and the lifetime of bulk recommendation, respectively. Table 3 tabulates these measurements and fitting results of the three films. These values are about the same as the CdTe films grown by MOCVD on $\mathrm{SiO}_{2} / \mathrm{Si}$ and graphene substrates[58]. Table 3 lists the fit of the TRPL curve measured at $1.47 \mathrm{eV}$ or 842 nm peak.

A sample of $\sim 500 \mathrm{~nm}$ thick CdTe on $\sim 200 \mathrm{~nm}$ CdS/mica was also prepared. We named this sample as the $500 \mathrm{~nm}$. The PL and TRPL spectra were measured from this $500 \mathrm{~nm}$ sample (plot not shown here). The analysis results of PL and TRPL from this sample are listed in Table 3. The PL spectrum of the $500 \mathrm{~nm}$ sample still shows two PL peaks, one at $\sim 1.52 \mathrm{eV}$, but the $2^{\text {nd }}$ peak position shifts to $1.65 \mathrm{eV}(\sim 750 \mathrm{~nm})$ from $1.47 \mathrm{eV}$ for the $2 \mu \mathrm{m}$ sample. The FWHM broadens to $\sim 123 \mathrm{~nm}$ that is one order of magnitude larger than the $20 \mathrm{~nm}$ FWHM for the $2 \mu \mathrm{m}$ sample. The decay constants $\tau_{1}$ and $\tau_{2}$ associated with $\sim 1.52 \mathrm{eV}$ and $1.65 \mathrm{eV}$ peaks for $500 \mathrm{~nm}$ sample are similar to that of the $2 \mu \mathrm{m}$ sample and listed in Table 3 . 
The change in PL spectra between the $500 \mathrm{~nm}$ sample and the $2 \mu \mathrm{m}$ sample can be understood from the inter-diffusion of S into CdTe and Te into CdS. The inter-diffusion at the junction of CdTe and CdS has been experimentally verified by our TEM EDS measurement presented earlier in the TEM section as well as by AES[55], XPS and SIM[40] in the literature. For the $400^{\circ} \mathrm{C}$ grown $\mathrm{CdTe} / \mathrm{CdS}$ junction, the S element diffuses into the CdTe film about $250 \mathrm{~nm}$ distance from the interface junction. See Fig. 5(c). The atomic concentration of S decays with distance into the CdTe film. In addition, the Te element diffuses from the CdTe film into the CdS film although the Te atomic concentration in the CdS film is less than the $\mathrm{S}$ atomic concentration in the CdTe film. This means $\mathrm{CdS}_{x} \mathrm{Te}_{1-x}$ alloy film $(0<x<1)$ could form if $\mathrm{S}$ substitutes the Te. From the decay of $\mathrm{S}$ atomic concentration away from the CdS and CdTe interface junction, the $\mathrm{S}$ concentration $x$ reaches zero at $\sim 250 \mathrm{~nm}$ into the $500 \mathrm{~nm}$ thick CdTe film. Similarly S decays into the CdTe film $250 \mathrm{~nm}$ in the $2 \mu \mathrm{m}$ thick CdTe. The rest of the $1.75 \mu \mathrm{m}$ thick CdTe has negligible $\mathrm{S}$. This means the $x$ value determined under the same optical penetration depth of the incident photons should give a higher $x$ for the $500 \mathrm{~nm}$ thick CdTe film than that of the $2 \mu \mathrm{m}$ thick CdTe film. One can extract the $x$ value from the $x$ dependent optical bandgap change.

Literature reports that the optical bandgap $\mathrm{E}_{\mathrm{g}}(x)$ of the $\mathrm{CdS}_{x} \mathrm{Te}_{1-x}$ alloy depends on the mole fraction $x[56,57]$. When $x=0$ the $\mathrm{E}_{\mathrm{g}}(0)$ is for single phase CdTe and when $x=1$ the $\mathrm{E}_{\mathrm{g}}(1)$ is for single phase CdS. In between 0 and 1 an equation $\mathrm{E}_{\mathrm{g}}(x)=1.51-1.01 x+1.74 x^{2}$ with $5 \%$ uncertainty was fitted from 19 optical bandgap data points from the $\mathrm{CdS}_{x} \mathrm{Te}_{1-x}$ film made from mixed crystals of CdTe and CdS[56]. Another bowing equation $\mathrm{E}_{\mathrm{g}}(x)=\mathrm{E}_{\mathrm{o}}+\left(\mathrm{E}_{1}-\mathrm{E}_{0}-\mathrm{b}\right) x+\mathrm{b} x^{2}$ has been obtained from a fit of 125 optical bandgap data points from nine literature references that give $\mathrm{E}_{\mathrm{o}}=1.54 \pm 0.01 \mathrm{eV}, \mathrm{E}_{1}=2.36 \pm 0.02 \mathrm{eV}$, and $\mathrm{b}=1.88 \pm 0.07 \mathrm{eV}$ [57]. Using these two equations, we extracted the $x$ value from our measured $E_{\mathrm{g}}=1.47 \mathrm{eV}$ from the $2 \mu \mathrm{m}$ sample to be $5-9 \%$ and the $x$ value from our measured $\mathrm{E}_{\mathrm{g}}=1.65 \mathrm{eV}$ from $500 \mathrm{~nm}$ sample to be $65-70 \%$. Therefore, one can use the change in the measured $\mathrm{E}_{\mathrm{g}}$ from PL to estimate the $x$ value in the $\mathrm{CdS}_{x} \mathrm{Te}_{1-x}$ alloy film. The fact that two PL peaks are observed in all samples with one unchanged peak position corresponding to $\mathrm{E}_{\mathrm{g}}=1.52 \mathrm{eV}$ for CdTe and one shifting peak corresponding to the $\mathrm{CdS}_{x} \mathrm{Te}_{1-x}$ alloy crystals implies that there is a mixture of CdTe crystals and $\mathrm{CdS}_{x} \mathrm{Te}_{1-x}$ alloy crystals in each sample. The fact the FWHM of $1.65 \mathrm{eV}$ PL peak from the $500 \mathrm{~nm}$ sample is broadened by one order of magnitude to $\sim 123 \mathrm{~nm}$ from the $\sim 20 \mathrm{~nm}$ FWHM of $1.47 \mathrm{eV}$ PL peak from the $2 \mu \mathrm{m}$ sample also supports that within the penetration depth of PL detection there is a wider range of $x$ value in the $\mathrm{CdS}_{x} \mathrm{Te}_{1-x}$ alloy of the $500 \mathrm{~nm}$ sample.

\section{(g) Photocurrent response of CdS/mica and CdTe/CdS/mica}

Figure 7 (a)shows the setup of photocurrent $(I) v s$. drain-source voltage $\left(V_{D S}\right)$ or photocurrent response $(I)$ vs. time $(t)$ measurement when light is switched on/off. Figs. 7 (b) shows collected $I$ $V_{D S}$ curves from the $2 \mu \mathrm{m}$ thick CdTe film on CdS on mica sample under dark and three different lamp illumination intensity. All curves are almost linear, indicating good Ohmic contacts. The inverse of the slope from the $I-V_{D S}$ gives the resistance. The resistance of the $2 \mu \mathrm{m} C d T e$ films under $30 \mathrm{~mW} / \mathrm{cm}^{2}$ illumination is $32.5 \mathrm{M} \Omega$. Not shown here are the $I-V_{D S}$ for the $200 \mathrm{~nm} \mathrm{CdS}$ film and $500 \mathrm{~nm}$ thick CdTe film on CdS. The resistances under $30 \mathrm{~mW} / \mathrm{cm}^{2}$ illumination are 20.4 and 281.6 M $\Omega$, respectively. Figs. 7(c) and (d) are measured photocurrent responses vs. time under the on/off illumination intensity of $30 \mathrm{~mW} / \mathrm{cm}^{2}$ for the $200 \mathrm{~nm}$ CdS film and the 2 $\mu \mathrm{m}$ CdTe film on CdS samples, respectively at different $V_{D S}$ of 10, 5 and $2 \mathrm{~V}$. Each curve 
reaches the same repeated intensity level when the light is on indicating the response is reversible and stable. Our measured photoresponse decay behavior was fitted by a function $I=I_{d}+\left(I_{0}-I_{d}\right) e^{-\left(\frac{t-t_{0}}{\tau}\right)^{\beta}},(0<\beta<1)[59]$, where $I_{0}$ is the current at the instant when the light is turned off at time $t_{0}, I_{d}$ is the measured dark current when the light is off, $\tau$ is a characteristic constant for the decay of the photocurrent, and $\beta$ is the decay exponent. Table 4 lists the result of fit under three bias voltages.

\section{CdS film}

We will discuss the result using the $10 \mathrm{~V}$ bias voltage. The fitted time $\tau$ for the CdS film is on the order of $1 \mathrm{sec}$. The data points collection step size is $0.002 \mathrm{~s}$. The fitted value of $\beta$ is about 0.5 depending on the bias voltage. Literature report of the decay time of a single crystal CdS measured at room temperature is a few sec[60], where the decay time is determined from the time when the photocurrent decays to $(1-1 / e) \approx 57 \%$ of the original value. Note this single crystal CdS was first heat treated in a sulfur atmosphere and then in a vacuum. If a single crystal $\mathrm{CdS}$ is heat treated in air, the decay time is reduced to sub sec. In other words, the decay time depends on the treatment of a sample that may change the density of traps relative to the density of free carriers. Such trapping states may have their origin in the forbidden gap of CdS as a result of impurity incorporation/gaseous chemisorption/lattice defects and/or their complex aggregates. Trapping lengthens the decay time as well by slowly releasing the trapped electrons after termination of illumination. If the density of traps is low relative to that of free carrier density, the response time will be dominated by the recombination process of the electrons and holes with a short decay time. The decay time also depends on the excitation light intensity. A higher intensity will excite more free carriers and the decay time is dominated by free carriers. For the same CdS single crystal, it also depends on the fabrication method. For example, the decay time for chemically deposited CdS film ranges from a few to tens sec[61]. Our measured response time of the epitaxial CdS film is consistent with values reported for single crystal CdS[60]. This implies that our epitaxial CdS film has a high quality that is reflected in the absence of defect level in the PL spectrum. The decay exponent $\beta$ value less than 1 means that there are two distinct time periods, $t<\tau$ and $t>\tau$. For $t<\tau$, the current decay is fast due to the recombination of electrons and holes. For $t>\tau$, the current decay is slow due to trapped electrons are being untrapped[59, 62].

The photocurrent on/off ratio is defined as $\Delta I_{\text {photon }} / I_{\text {dark }}$, where $\Delta I_{\text {photon }}=I_{\text {light }}-I_{\text {dark }}, I_{\text {light }}$ and $I_{\text {dark }}$ are light-on current and light-off current, respectively. Our measured on/off ratio is in the tens, much lower compared with the $10^{5}$ ratio for CdS nanosheet where the $I$ - $V$ curve is non-linear with the bias voltage. Their high intensity (light-on) and the low intensity (light-off) are $10^{-5} \mathrm{~A}$ and $10^{-11} \mathrm{~A}$, respectively, using $5 \mathrm{~mW}$ laser power and $5 \mathrm{~V}$ bias[63]. For chemically deposited CdS thin films under AM2 solar illumination, the on/off ratio is $10^{6}$ to $10^{7}$ [61].

The detector's current responsivity $R$ is defined as the photocurrent generated per unit area of the incident lightpoweron the effective area of a photo conductor. $R$ is expressed as $R=\Delta I_{\text {photon }} / P S$, where $\Delta I_{\text {photon }}$ is the difference between the currents with light-on and light-off. $P$ is the light power and $S$ is the effective area of the photodetector. The calculated $R$ values for three biases are shown in Table 4 . The value of $R$ increases with increasing bias voltage $V_{D S}$. The calculated 
Table 4 Decay time $\tau$ and decay exponent $\beta$ extracted from the fits of measured photoresponse $v s$. time curves, photocurrent on/off ratio, and calculated current responsivity $R$ under various source-drain voltage $V_{D S}$.

\begin{tabular}{|l|l|l|l|l|l|}
\hline Sample & $V_{D S}(\mathrm{~V})$ & $\tau$ & $\beta$ & $\begin{array}{l}\text { Photocurrent On/off } \\
\text { ratio }\end{array}$ & $\begin{array}{l}\text { Responsivity } R \\
(\mu \mathrm{A} / \mathrm{W})\end{array}$ \\
\hline \multirow{2}{*}{$\begin{array}{l}200 \mathrm{~nm} \\
\mathrm{CdS} / \mathrm{mica}\end{array}$} & 10 & $1.007 \pm 0.002 \mathrm{~s}$ & $0.520 \pm 0.001$ & $19.71 \pm 1.74$ & 163.90 \\
\cline { 2 - 6 } & 5 & $1.106 \pm 0.002 \mathrm{~s}$ & $0.714 \pm 0.003$ & $10.04 \pm 1.42$ & 64.60 \\
\cline { 2 - 6 } & 2 & $1.000 \pm 0.002 \mathrm{~s}$ & $0.793 \pm 0.005$ & $7.89 \pm 1.64$ & 28.79 \\
\hline \multirow{2}{*}{$\begin{array}{l}2 \mu \mathrm{m} \mathrm{CdTe} / \\
200 \mathrm{~nm}\end{array}$} & 10 & $0.98 \pm 0.05 \mathrm{~ms}$ & $0.418 \pm 0.021$ & $303.49 \pm 3.07$ & 101.16 \\
\cline { 2 - 6 } $\mathrm{CdS} / \mathrm{mica}$ & 5 & $0.99 \pm 0.05 \mathrm{~ms}$ & $0.480 \pm 0.013$ & $143.85 \pm 1.04$ & 47.95 \\
\cline { 2 - 6 } $\begin{array}{l}500 \mathrm{~nm} \\
\mathrm{CdTe} /\end{array}$ & 2 & $0.99 \pm 0.05 \mathrm{~ms}$ & $0.511 \pm 0.019$ & $53.68 \pm 0.83$ & 17.89 \\
\cline { 2 - 6 } $\begin{array}{l}200 \mathrm{~nm} \\
\mathrm{CdS} / \mathrm{mica}\end{array}$ & 5 & $0.99 \pm 0.05 \mathrm{~ms}$ & $0.400 \pm 0.016$ & $34.25 \pm 1.15$ & 13.01 \\
\cline { 2 - 6 } & 2 & $1.01 \pm 0.05 \mathrm{~ms}$ & $0.611 \pm 0.053$ & $21.85 \pm 1.29$ & 7.28 \\
\hline
\end{tabular}

$R$ is $\sim 163.9 \mu \mathrm{A} / \mathrm{W}$ for $V_{D S}=10 \mathrm{~V}$. Our responsivity value $R$ of epitaxial CdS film is larger than $\sim 1 \mu \mathrm{A} / \mathrm{W}$ measured from $\sim 300 \mathrm{~nm}$ thick polycrystalline $\mathrm{CdS}$ films with $\sim 8 \mathrm{~nm}$ size crystals on plastic substrates[64] or $10^{-4}-10^{-5} \mathrm{~A} / \mathrm{W}$ measured from 300 - $400 \mathrm{~nm}$ thick polycrystalline CdS films with tens nm size crystals on p-GaAs substrate[65]. Note that the $R$ value depends on film texture, incident photon wavelength, contacts, bias voltage, photodetector design and size[66].

\section{CdTe film on CdS film}

Figures 7(c) and (d) shows that the photocurrents measured from CdTe on CdS are tens of nA and hundreds of $\mathrm{nA}$ for the $500 \mathrm{~nm}$ and $2 \mu \mathrm{m}$ thick CdTe films, respectively. The photocurrent reaches the same level under the light-on condition indicating reversible and stable responses. The fitted decay time $\tau$ for the $500 \mathrm{~nm}$ or $2 \mu \mathrm{m}$ thick CdTe film on CdS is $\sim 1 \mathrm{~ms}$, orders of magnitude shorter than the $1 \mathrm{sec}$ for CdS. The data collection step size is $0.05 \mathrm{~ms}$. See Table 4 . The value of $\beta$ is $\sim 0.4$, again, implying one fast and one slow decay processes. The on/off ratio is in the tens for the $500 \mathrm{~nm}$ thick CdTe film and hundreds for the $2 \mu \mathrm{m}$ thick CdTe film. Our decay time is shorter and the on/off ratio is higher than previous literature reports of film or micron-size or nano-size structures. For example, the photoresponse of $365 \mathrm{~nm}$ UV light incident on a CdTe film/graphene device with a 10 microns gap distance between electrodes shows an Ohmic behavior in the $I-V$ curves. The average response time (the time needed for the photocurrent to reach $90 \%$ of the saturated current value from the baseline) is $10.4 \mathrm{~s}$. The on-off ratio of the CdTe photodetector is $~ 2.8$ under light intensity of $269 \mu \mathrm{W} / \mathrm{cm}^{2}$ and $1 \mathrm{~V}$ bias[67]. Photodetectors made of CdTe in micron-size structures have also been reported. For examples, CdTe microwires have a rise time and a decay time of $7.7 \mathrm{~s}$ and $<0.06 \mathrm{~s}$, respectively[49]; the on-off ratio for a field effect transistor made of a CdTe microwire is 2 to 3 at $20 \mathrm{~V}$ bias under the UV light[68]. For nanostructures, examples are: for a CdTe nanoribbon the ratio is 1.1 at $10 \mathrm{~V}$ bias voltage under light $(400-1000 \mathrm{~nm})$ intensity of $637 \mu \mathrm{W} / \mathrm{cm}^{2}[51]$; for CdTe nanorods the ratio is 15 at $1.5 \mathrm{~V}$ bias under white light (metal halide lamp)[69]; and for CdTe nanoflake arrays on fluorine doped tin oxide glass the ratio is $<10$ at $-1 \mathrm{~V}$ bias voltage under white light illumination[70]. 


\section{(h) Hall mobility of CdS film and CdTe/CdS film}

The Hall measurement of our $200 \mathrm{~nm}$ thick CdS film at room temperature under $1 \mathrm{nA}$ or $3 \mathrm{nA}$ and 0.4000 Tesla applied magnetic field gave n-type carrierswith an average concentration of $(1.3 \pm 0.5) \times 10^{17} / \mathrm{cm}^{3}$ and average mobility of $344 \pm 76 \mathrm{~cm}^{2} / \mathrm{V} \cdot \mathrm{s}$. This value is slightly higher than $230 \mathrm{~cm}^{2} / \mathrm{V}$.s of a micron thick CdS film grown by hot wall epitaxy on single crystal $\mathrm{SrF}_{2}$ with n-type indium dopant and a concentration of $2 \times 10^{17} / \mathrm{cm}^{3}$ to $3 \times 10^{18} / \mathrm{cm}^{3}[71]$. Our mobility is one or two orders higher than the tens of $\mathrm{cm}^{2} / \mathrm{V} \bullet \mathrm{s}$ value measured from a micron thick CdS film grown on glass substrates by thermal evaporation[72, 73]. We attribute our measured high mobility to our high quality epitaxial CdS film grown on single crystal mica substrate where no defect peak was observed in the PL spectrum of CdS film. For CdS films used in solar cell device they should be conductive (dopant concentration $\sim 10^{16} \mathrm{~cm}^{-3}$ ), thin enough (50-100 nm) to allow high transmission, and uniform in order to suppress short circuit effects[37]. Our CdS films fit these criteria for CdTe/CdS photovoltaic devices.

For the $500 \mathrm{~nm}$ CdTe on CdS film the measured room temperature electron mobility and carrier concentration under $1 \mathrm{nA}$ and 0.4000 Tesla applied magnetic field are $364 \pm 90 \mathrm{~cm}^{2} / \mathrm{V} \cdot \mathrm{s}$ and $(1.6$ $\pm 0.2) \times 10^{14} / \mathrm{cm}^{3}$ n-type, respectively. As the CdTe layer was grown on CdS layer, the measured value of mobility is considered to have contributions from both the layers. For a comparison, the mobility of a single crystal CdTe is $\sim 1000 \mathrm{~cm}^{2} / \mathrm{V} \cdot \mathrm{s}[74]$. We attribute this difference to the grain boundary scattering in the alloying of CdTe and CdS films. However, our mobility value is much higher than the reported electron drift mobility ranging from $0.1-1 \mathrm{~cm}^{2} / \mathrm{V} \cdot \mathrm{s}$ measured from polycrystalline CdTe/CdS solar cells[75].

\section{Conclusion}

We demonstrated that CdS films can be grown epitaxially on mica despite of very large lattice mismatch through van der Waals interaction using thermal evaporation of CdS with no intentional substrate heating. The CdS/mica is then used as a substrate to grow epitaxial CdTe films using MOCVD at $400^{\circ} \mathrm{C}$ despite a large ( 10\%) lattice mismatch between CdTe and CdS. Two photoluminescence (PL) peaks in the $2 \mu$ m thick CdTe films were observed, one at $1.52 \mathrm{eV}$ which is the optical bandgap of CdTe and the other one at $1.47 \mathrm{eV}$ which is consistent with an interfacial layer of $\mathrm{CdS}_{1-\mathrm{x}} \mathrm{Te}_{\mathrm{x}}$ alloyed at the $\mathrm{CdTe} / \mathrm{CdS}$ interface. This interdiffusions of $\mathrm{S}$ and $\mathrm{Te}$ are also directly observed by EDS. Our unique RHEED pole figure analysis shows that the near surface in-plane texture of $2 \mu \mathrm{m}$ thick CdTe film is better than the average texture of the entire 2 $\mu \mathrm{m}$ thick film. The time resolved PL of the $\mathrm{CdTe} / \mathrm{CdS} /$ mica films reveals a bi-exponential decay with a fast decay time and slow decay time component dominated by surface recombination in the CdTe film and carrier recombination at the interface in $\mathrm{CdS}_{x} \mathrm{Te}_{1-x}$, respectively. The photoresponse of the CdTe films is in the ms regime with a high on/off ratio. The measured room temperature Hall mobility of the heteroepitaxial CdTe/CdS films is in a few hundreds of $\mathrm{cm}^{2} / \mathrm{V} \bullet \mathrm{s}$ for $10^{14} / \mathrm{cm}^{3} \mathrm{n}$-type carrier concentration, orders of magnitude higher than that from polycrystalline CdTe/CdS films. The use of van der Waals substrate to grow 3D epitaxial semiconductor films with good electrical and optical properties offers an alternative way to grow high quality optoelectronic films. 


\section{Acknowledgement}

This work is supported by the US NSF DMR-1305293, the New York State Foundation of

Science, Technology and Innovation (NYSTAR) through Focus Center-New York C130117, and Rensselaer. Y.W. and J.S. were supported by NSF Awards under CMMI 1550941 and CMMI 1635520. TEM and EDS studies were carried out in whole at Center for Functional

Nanomaterials, BNL, operated by the U.S. DOE, Office of Basic Sciences under contract No. DE-SC0012704. 


\section{For Table of Contents Use Only}

\section{Surface and interface of epitaxial CdTe film on CdS buffered van der Waals mica substrate}

Y.-B. Yang, L. Seewald, Dibyajyoti Mohanty, Y. Wang, L.H. Zhang, K. Kisslinger, Weiyu Xie, J. Shi, I. Bhat, Shengbai Zhang, T.-M. Lu, and G.-C. Wang
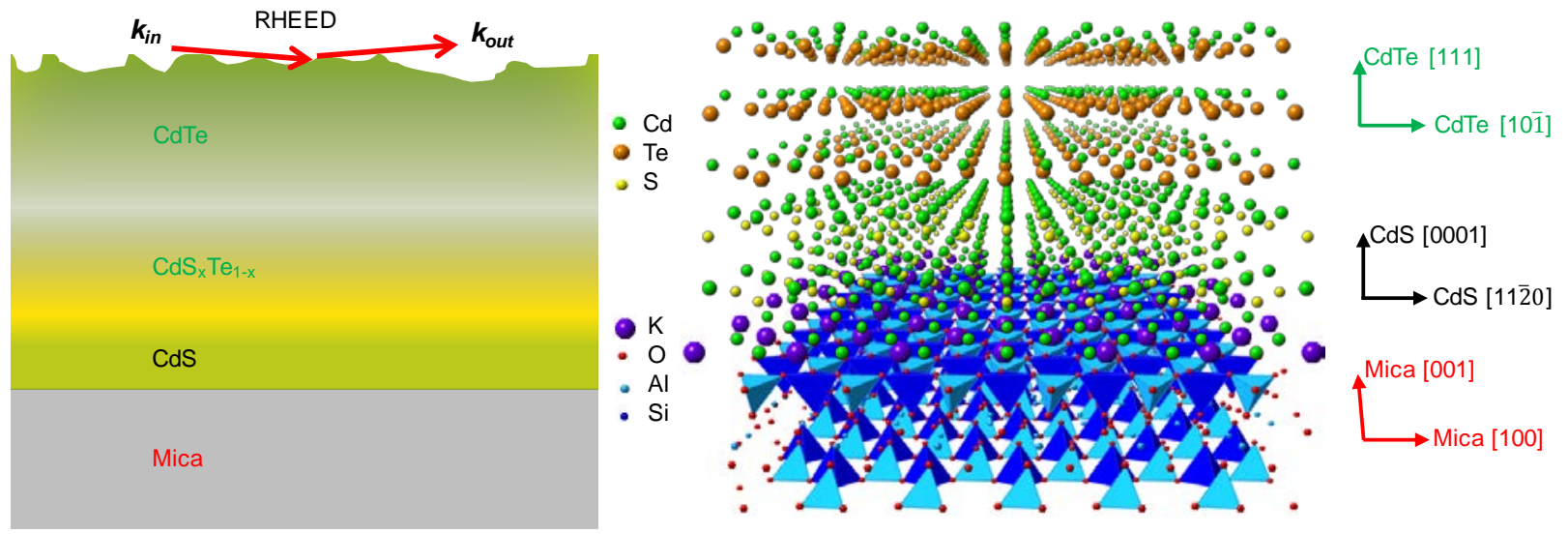

Description: Schematic figures show the epitaxy growth of CdTe on CdS on Mica with $\mathrm{CdS}_{\mathrm{x}} \mathrm{Te}_{1}$ $x$ alloyed layers at the interface of CdTe and CdS. The thickness is not to scale. The out-of-plane and in-plane epitaxial directions of the heteroepitaxial films were characterized by reflection high energy electron diffraction pole figure analysis. 
Figures and figure captions
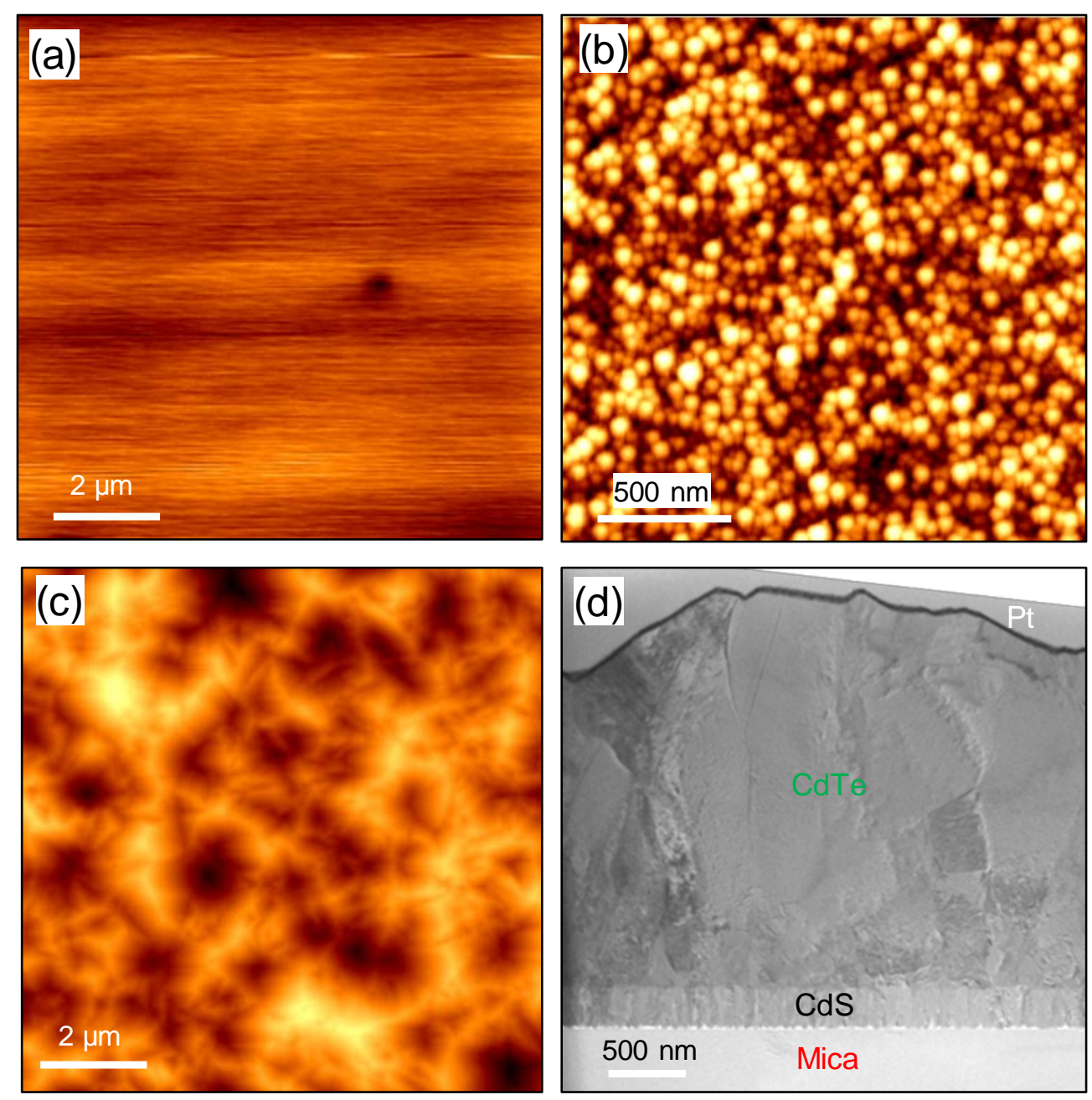

Fig. 1 Atomic force microscopy top view images of (a) mica substrate, (b) CdS film, and (c) CdTe film ( $2 \mu \mathrm{m}$ thick). The scale bars are $2 \mu \mathrm{m}, 500 \mathrm{~nm}$, and $2 \mu \mathrm{min}$ (a), (b) and (c), respectively. (d) TEM cross section view of $\sim 2 \mu \mathrm{m}$ CdTe film on $\sim 200 \mathrm{~nm}$ CdS film on mica, the same sample shown in (c). The contrast in different area is due to the diffraction contrast from different grains. The scale bar is $500 \mathrm{~nm}$. 


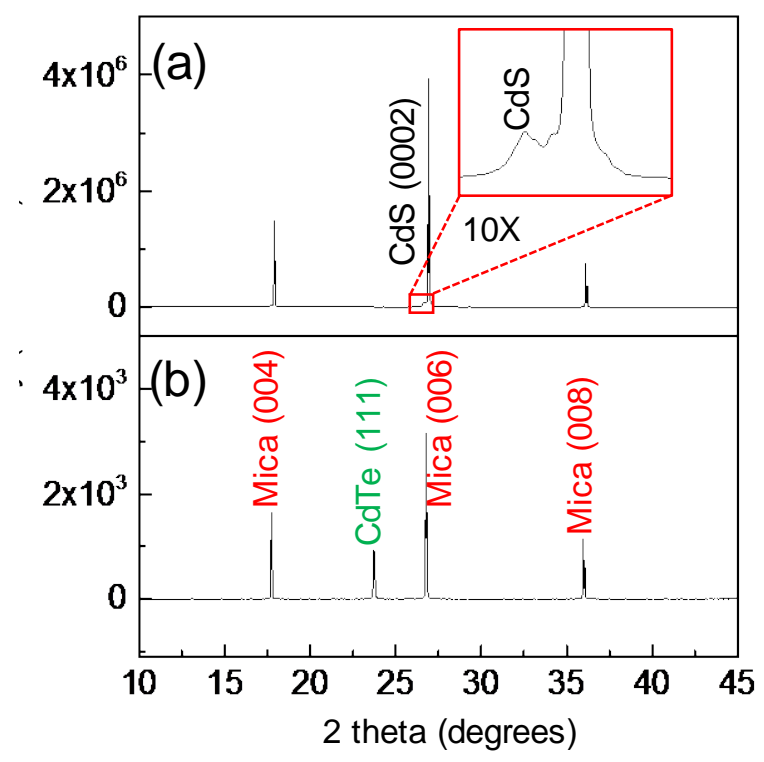

Fig. 2 X-ray $\theta$ vs. $2 \theta$ spectra of (a) CdS(0001) film on mica(001) and (b) CdTe(111) film on CdS(0001) film on mica(001). The peaks with strong intensity from single crystal mica are seen in all spectra. The inset in (a) is a magnified (ten times) spectrum of the CdS (0002) peak near the mica (006) peak. The difference in counts is due to different primary X-ray intensity used in the measurements. 


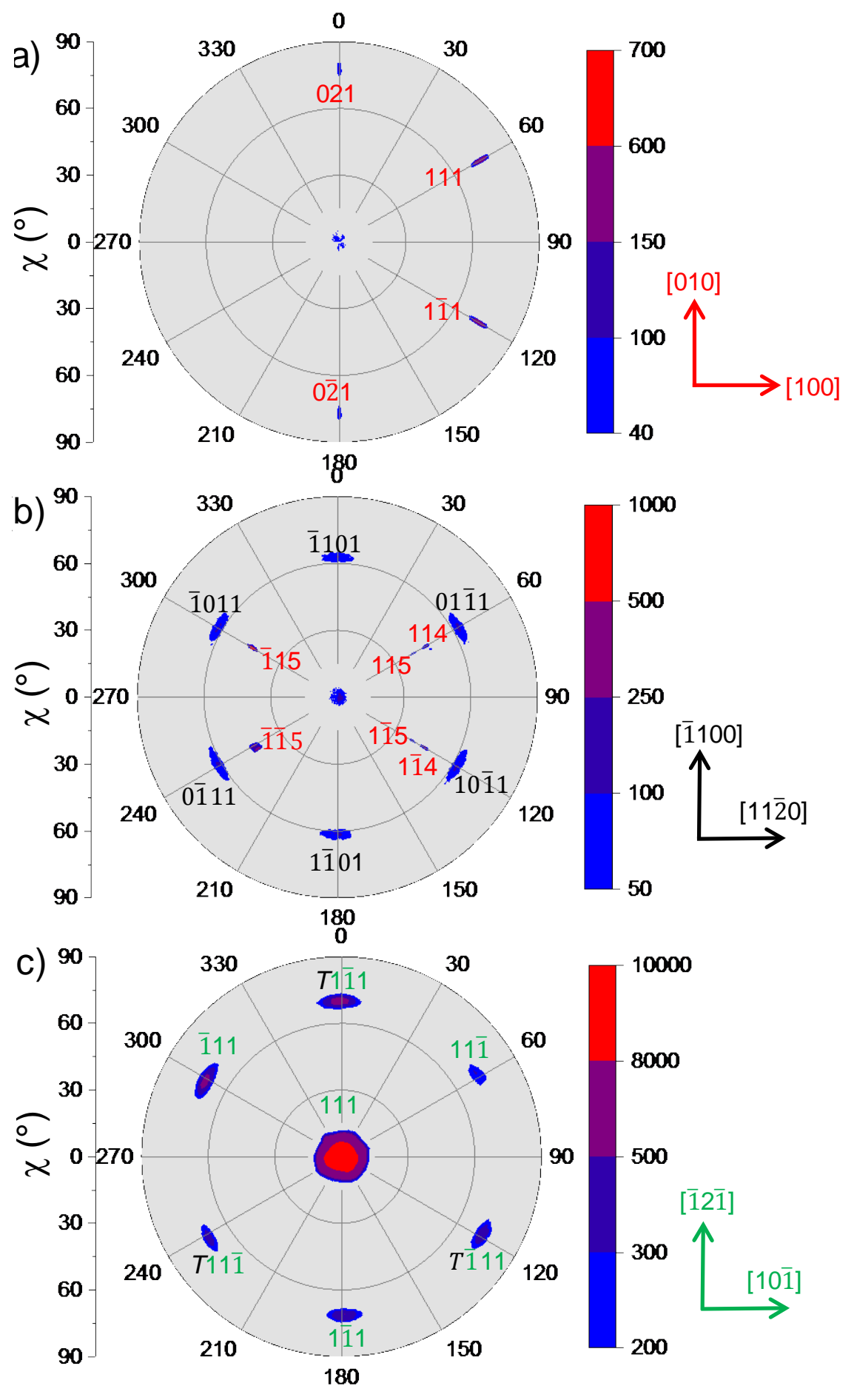

Fig. 3 X-ray pole figure of (a) mica $\{111\}$, (b) CdS $\{01 \overline{1} 1\}$, and (c) CdTe $\{111\}$ poles. The $0^{\circ}$ azimuthal direction is defined as the [010] direction of mica(001) along the vertical direction of the page. The range of chi $(\chi)$ angle is from 0 (surface normal) to $90^{\circ}$. The red, black, and green labels are for mica, CdS, and CdTe poles, respectively. The "T" in (c) means twins. The real space directions are indicated to the right-side of color bars associated with the intensity of X-ray pole figure. 

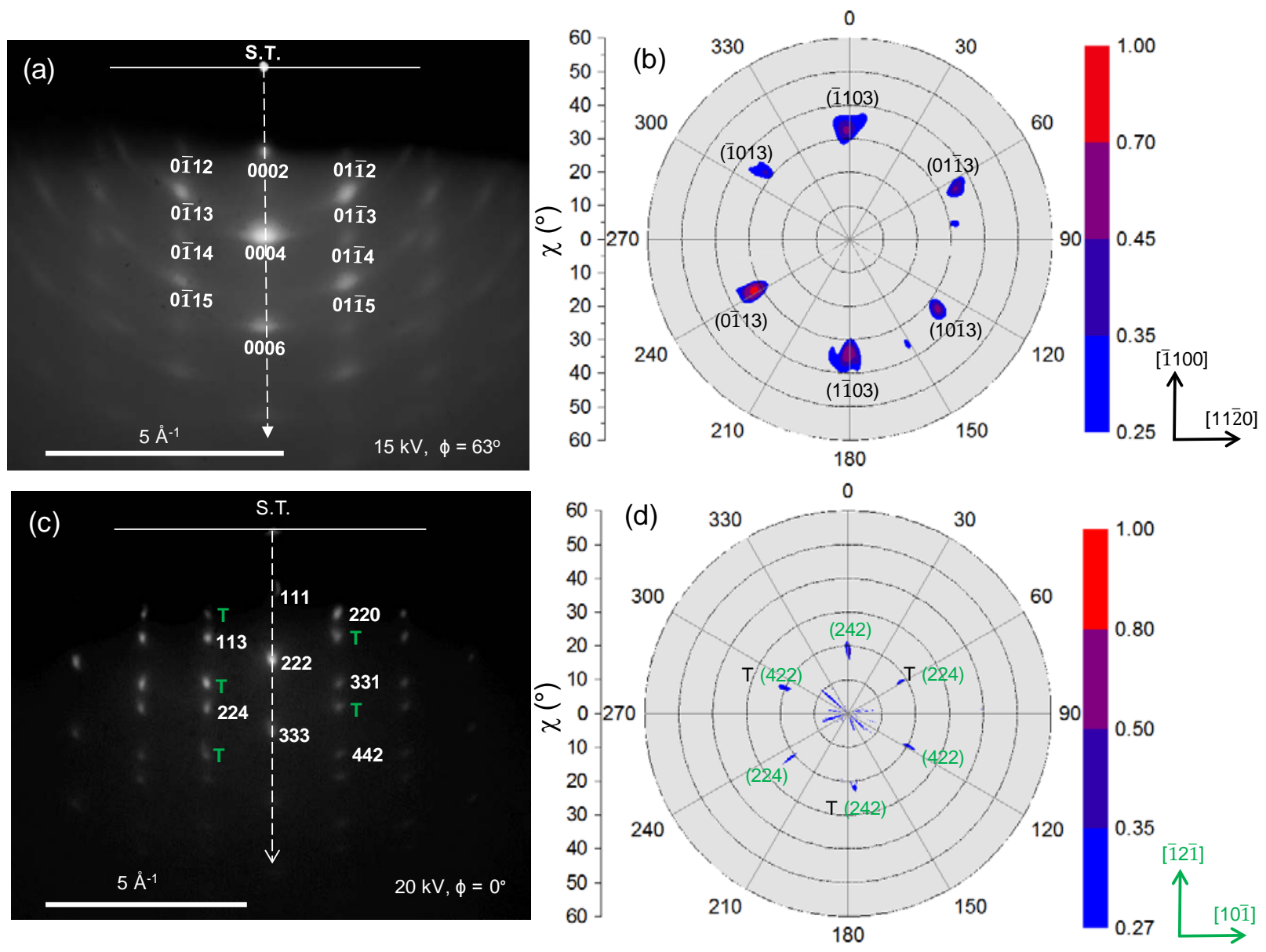

Fig. 4 (a) Reflection high energy electron diffraction (RHEED) pattern of CdS(0001) film using a $15 \mathrm{keV}$ primary electron beam energy incident at azimuthal angle $\phi=63^{\circ}$. S.T. means the straight through electron beam. The white horizontal line indicates the shadowing edge of the RHEED pattern. The scale bar is $1 \AA^{-1}$. (b) RHEED pole figure of CdS $\{01 \overline{1} 3\}$ poles. (c) RHEED pattern of CdTe(111) film using a $20 \mathrm{keV}$ primary electron beam energy incident at azimuthal angle $\phi=0^{\circ}$. Twin spots are indicated by green Ts. The scale bar is $5 \AA^{-1}$. (d) RHEED pole figure of CdTe $\{224\}$ poles. Three twin poles among six poles are labeled by Ts. Note the range of $\chi$ angle is plotted from 0 (surface normal) to $60^{\circ}$. The real space directions are indicated to the right-side of color bars (associated with the normalized intensity of RHEED pole figure). 

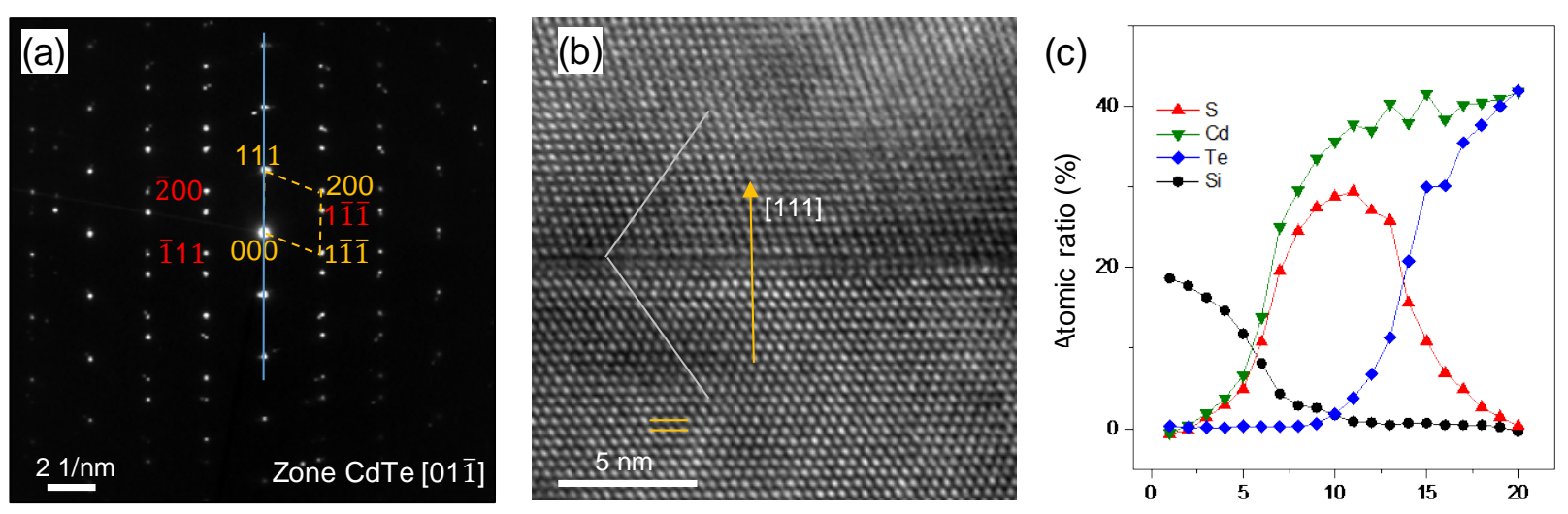

Fig. 5 (a) TEM diffraction pattern of CdTe observed along the [011] zone axis that is perpendicular to the [111] direction. Twin spots are labeled in red. The scale bar is $2 \mathrm{~nm}^{-1}$. (b) High resolution TEM image of CdTe showing existence of twins. The interlayer spacing $d_{111}$ is between two parallel lines. The scale bar is $5 \mathrm{~nm}$. (c) Atomic concentration profiles of Si, S, Cd, and Te across the interface of mica and CdS and the interface of CdS and CdTe. The adjacent distance between two data points is $\sim 35 \mathrm{~nm}$. 

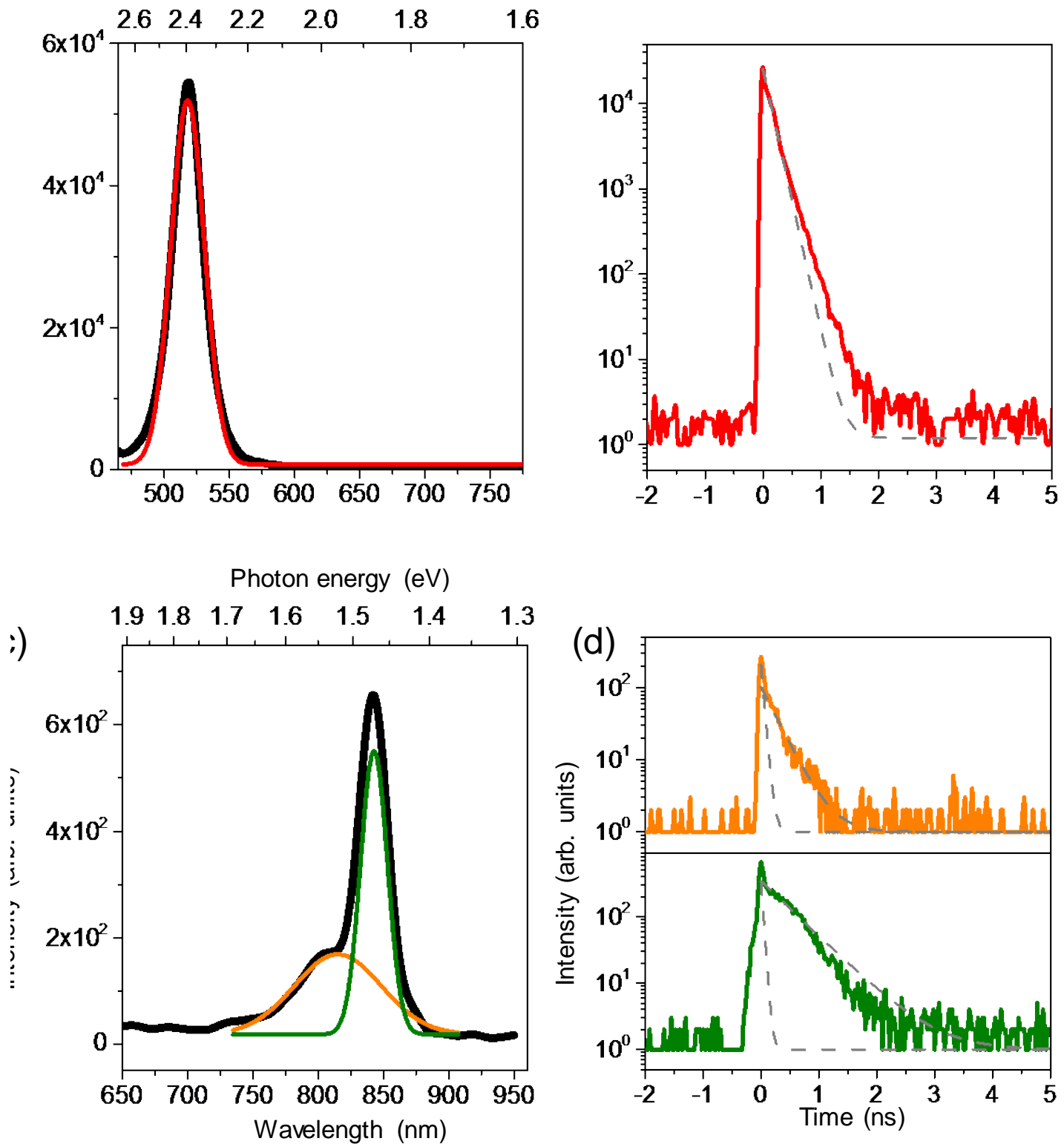

Fig. 6 (a) Photoluminescence (PL) spectrum of $200 \mathrm{~nm}$ thick CdS(0001) film (black curve) on mica(001) with a peak at $518 \mathrm{~nm}$ (fit from the red Gaussian curve) and (b) time resolved PL of CdS film on mica. A single decay function (dashed curve) fit of the CdS PL peak at $518 \mathrm{~nm}$ gives a decay time of $0.14 \pm 0.02$ ns. (c) PL spectrum of $2 \mu \mathrm{m}$ thick CdTe(111) film (black curve) on $200 \mathrm{~nm}$ thick CdS(0001) film on mica(001) with two peaks at $815 \mathrm{~nm}$ (fit from orange Gaussian curve) and $842 \mathrm{~nm}$ (fit from green Gaussian curve), and (d) time resolved PL of $2 \mu \mathrm{m}$ thick CdTe film on CdS film on mica. A two-component (two dashed curves) fit in the time decay spectrum of CdTe film on CdS on mica at $815 \mathrm{~nm}$ (orange curve) and $842 \mathrm{~nm}$ (green curve) gives a fast initial decay $\tau_{1}$ and followed by a slow decay $\tau_{2}$. Note the intensity in the vertical axis is plotted in log scale and the difference between data and fit in low intensity part is magnified compared with that at high intensity. 

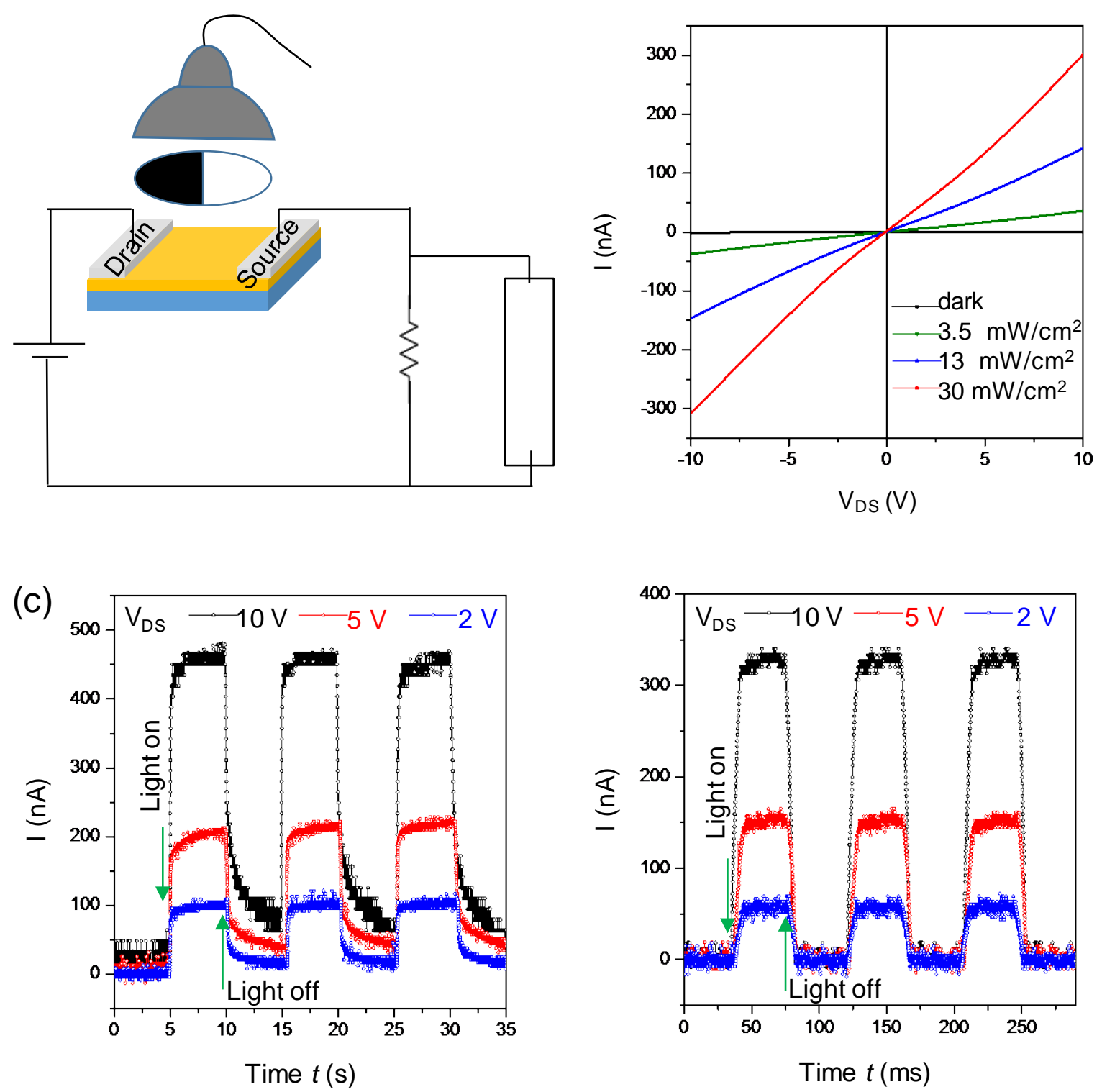

Fig.7 (a) Experimental setup for photocurrent vs. drain-source voltage ( $\left.I-V_{D S}\right)$ measurement and photocurrent response $v s$. time $t$ measurement using a lamp and a mechanical chopper with a variable frequency, (b) $I-V_{D S}$ of $2 \mu \mathrm{m}$ CdTe film on CdS on mica under dark and light illumination at $3.5,13$, and $30 \mathrm{~mW} / \mathrm{cm}^{2}$. Cycles of photocurrent responses of (c) $200 \mathrm{~nm} \mathrm{CdS}$ film on mica and (d) $2 \mu \mathrm{m}$ CdTe film on $200 \mathrm{~nm}$ CdS film on mica film under $30 \mathrm{~mW} / \mathrm{cm}^{2}$ illumination at $V_{D S}=2,5$, and $10 \mathrm{~V}$. 


\section{References}

[1] N. Matsumura, T. Ohshima, J. Saraie, Y. Yodogawa, Preparation of CdTe thin films on Ge substrates by molecular beam epitaxy, J. Cryst. Growth, 71 (1985) 361-370.

[2] R. Sporken, M.D. Lange, J.P. Faurie, J. Petruzzello, Molecular-beam epitaxy of CdTe on large area Si(100), J. Vac. Sci. Technol. B, 9 (1991) 1651-1655.

[3] M.I. Abdalla, D.B. Holt, The epitaxial growth and strucutre of films of CeTe evaporated onto Ge, Phys. Stat. Sol. (a), 17 (1973) 267-279.

[4] G.M. Lalev, J. Wang, J.-W. Lim, S. Abe, K. Masumoto, M. Isshiki, Direct growth of CdTe(1 0 0) epilayers on Si(1 0 0) substrate by hot wall epitaxy, Appl. Surf. Sci., 242 (2005) 295-303.

[5] Q. Jiang, A.W. Brinkman, B.J. Cantwell, J.T. Mullins, F. Dierre, A. Basu, P. Veeramani, P. Sellin, Growth of Thick Epitaxial CdTe Films by Close Space Sublimation, J. Electron. Mater., 38 (2009) 1548-1553.

[6] O. Toma, L. Ion, M. Girtan, S. Antohe, Optical, morphological and electrical studies of thermally vacuum evaporated CdTe thin films for photovoltaic applications, Solar Energy, 108 (2014) 51-60.

[7] W.-O. Seo, D. Kim, J. Kim, Flexible CdTe/CdS solar cells on thin glass substrates, Opt. Express, 23 (2015) A316-A321.

[8] L. Chen, J. Dash, P. Su, C.F. Lin, I. Bhat, T.-M. Lu, G.-C. Wang, Instrument response of reflection high energy electron diffraction pole figure, Appl. Surf. Sci., 288 (2014) 458- 465.

[9] S. Neretina, R.A. Hughes, N.V. Sochinskii, M. Weber, K.G. Lynn, J. Wojcik, G.N. Pearson, J.S. Preston, P. Mascher, Growth of CdTe/Si(100) thin films by pulsed laser deposition for photonic applications, J. Vac. Sci. Technol. A, 24 (2006) 606-611.

[10] R. Sporken, D. Grajewski, Y. Xin, F. Wiame, G. Brill, P. Boieriu, A. Prociuk, S. Rujirawat, N.K. Dhar, S. Sivananthan, Selective epitaxy of cadmium telluride on silicon by MBE, J.

Electron. Mater., 29 (2000) 760-764.

[11] D.J. Smith, S.C.Y. Tsen, Y.P. Chen, S. Sivananthan, J.B. Posthill, Growth and characterization of heteroepitaxial CdTe and ZnTe on Ge(001) buffer layers, Appl. Phys. Lett., 69 (1996) 2086-2088.

[12] Y. Yan, R.G. Dhere, K.M. Jones, M.M. Al-Jassim, Influence of substrate structure on the growth of CdTe thin films, J. Appl. Phys., 89 (2001) 5944-5948.

[13] J.E. Hails, G.J. Russell, A.W. Brinkman, J. Woods, Twin nucleation in layers of CdTe on \{lll\} CdTe grown by metalorganic vapor $\quad$; \$hAsфpфpPlaxs., 60 (1986) 2624-2625.

[14] M.Y. Simmons, P.D. Brown, K. Durose, MOVPE growth and characterisation of CdTe on CdS single crystal substrates, J. Cryst. Growth, 107 (1991) 664-669.

[15] P.-Y. Su, C. Lee, G.-C. Wang, T.-M. Lu, I.B. Bhat, CdTe/ZnTe/GaAs Heterostructures for Single-Crystal CdTe Solar Cells, J. of Electronic Mater., 43 (2014) 2895-2900.

[16] B. Ortner, G. Bauer, (111) CdTe epitaxy on (100) GaAs substrates, J. Cryst. Growth, 92 (1988) 69-76.

[17] J.P. Faurie, C. Hsu, S. Sivananthan, X. Chu, CdTe-GaAs(100) interface: MBE growth, rheed and XPS characterization, Surf Sci., 168 (1986) 473-482.

[18] F.A. Ponce, G.B. Anderson, J.M. Ballingall, Interface structure in heteroepitaxial CdTe on GaAs(100), Surf Sci., 168 (1986) 564-570.

[19] T. Siegrist, A. Segmüller, H. Mariette, F. Holtzberg, Growth of epitaxial films of CdTe and (Cd,Mn)Te on GaAs substrates, Appl. Phys. Lett., 48 (1986) 1395-1397. 
[20] P.-Y. Su, R. Dahal, G.-C. Wang, S. Zhang, T.-M. Lu, I.B. Bhat, Single-Crystal CdTe Homojunction Structures for Solar Cell Applications, J. Electron. Mater., 44 (2015) 3118-3123. [21] P.D. Brown, J.E. Hails, G.J. Russell, J. Woods, TEM studies of epitaxial CdTe and (Hg, Cd)Te grown by MOVPE on GaAs and CdTe substrates, J. Cryst. Growth, 86 (1988) 511-515. [22] S.M. Jovanovic, G.A. Devenyi, V.M. Jarvis, K. Meinander, C.M. Haapamaki, P. Kuyanov, M. Gerber, R.R. LaPierre, J.S. Preston, Optical characterization of epitaxial single crystal CdTe thin films on $\mathrm{Al}_{2} \mathrm{O}_{3}$ (0001) substrates, Thin Solid Films, 570, Part A (2014) 155-158.

[23] S. Neretina, Q. Zhang, R.A. Hughes, J.F. Britten, N.V. Sochinskii, J.S. Preston, P. Mascher, The role of lattice mismatch in the deposition of CdTe thin films, J. Electron. Mater., 35 (2006) 1224-1230.

[24] R. Lord, P. Su, I. Bhat, S. Zhang, T.-M. Lu, G.-C. Wang, Biaxially oriented CdTe films on glass substrate through nanostructured $\mathrm{Ge} / \mathrm{CaF}_{2}$ buffer layers, Mater. Express, 2 (2015) 095017 [25] C. Gaire, S. Rao, M. Riley, L. Chen, A. Goyal, S. Lee, I. Bhat, T.-M. Lu, G.-C. Wang, Epitaxial growth of CdTe thin film on cube-textured Ni by metal-organic chemical vapor deposition, Thin Solid Films, 520 (2012) 1862-1865.

[26] G.-C. Wang, L.H. Zhang, K. Kisslinger, C. Gaire, A. Goyal, I. Bhat, T.-M. Lu, Orientational domains in metalorganic chemical vapor deposited CdTe(111) film on cube-textured Ni, Thin Solid Films, 531 (2013) 217-221.

[27] W. Yuan, F. Tang, H.F. Li, T. Parker, N. LiCausi, T.-M. Lu, I. Bhat, G.-C. Wang, S. Lee, Biaxial CdTe/CaF ${ }_{2}$ films growth on amorphous surface, Thin Solid Films, 517 (2009) 66236628.

[28] A. Koma, Van der Waals epitaxy for highly lattice-mismatched systems, J. Cryst. Growth, 201-202 (1999) 236-241.

[29] Q. Wang, K. Xu, Z. Wang, F. Wang, Y. Huang, M. Safdar, X. Zhan, F. Wang, Z. Cheng, J. He, van der Waals Epitaxial Ultrathin Two-Dimensional Nonlayered Semiconductor for Highly Efficient Flexible Optoelectronic Devices, Nano Lett., 15 (2015) 1183-1189.

[30] Y. Wang, X. Sun, R. Shivanna, Y. Yang, Z. Chen, Y. Guo, G.-C. Wang, E. Wertz, F. Deschler, Z. Cai, H. Zhou, T.-M. Lu, J. Shi, Photon Transport in One-Dimensional Incommensurately Epitaxial CsPbX3 Arrays, Nano Lett., 16 (2016) 7974-7981. [31] M.I.B. Utama, Z. Peng, R. Chen, B. Peng, X. Xu, Y. Dong, L.M. Wong, S. Wang, H. Sun, Q. Xiong, Vertically Aligned Cadmium Chalcogenide Nanowire Arrays on Muscovite Mica: A Demonstration of Epitaxial Growth Strategy, Nano Lett., 11 (2011) 3051-3057.

[32] M.I.B. Utama, Q. Zhang, S. Jia, D. Li, J. Wang, Q. Xiong, Epitaxial II-VI Tripod Nanocrystals: A Generalization of van der Waals Epitaxy for Nonplanar Polytypic Nanoarchitectures, ACS Nano, 6 (2012) 2281-2288.

[33] M.I.B. Utama, Q. Zhang, J. Zhang, Y. Yuan, F.J. Belarre, J. Arbiol, Q. Xiong, Recent developments and future directions in the growth of nanostructures by van der Waals epitaxy, Nanoscale, 5 (2013) 3570-3588.

[34] D. Zubia, S.D. Hersee, Nanoheteroepitaxy: The Application of nanostructuring and substrate compliance to the heteroepitaxy of mismatched semiconductor materials, J. Appl. Phys., 85 (1999) 6492-6496.

[35] K.L. Chopra, I.H. Khan, Polymorphic transformation in epitaxial CdS films, Surf Sci., 6 (1967) 33-41.

[36] K.K. Muravyeva, I.P. Kalinkin, V.B. Aleskovsky, I.N. Anikin, Epitaxial growth of AIIBVI type compounds under quasi-equilibrium conditions, Thin Solid Films, 10 (1972) 355-362. 
[37] S.G. Kumar, K.S.R.K. Rao, Physics and chemistry of CdTe/CdS thin film heterojunction photovoltaic devices: fundamental and critical aspects, Energy Environ Sci., 7 (2014) 45-102. [38] Y.-P. Zhao, G.-C. Wang, T.-M. Lu, Characterization of amorphous and crystalline rough surface: principles and applications, Experimental Methods in the Physical Science, 37 (2001) Academic Press.

[39] Y. Wang, L. Seewald, Y.-Y. Sun, P. Keblinski, X. Sun, S. Zhang, T.-M. Lu, J.M. Johnson, J. Hwang, J. Shi, Nonlinear Electron-Lattice Interactions in a Wurtzite Semiconductor Enabled via Strongly Correlated Oxide, Adv. Mater., 28 (2016) 8975-8982.

[40] P. Boieriu, R. Sporken, A. Adriaens, Y. Xin, N.D. Browning, S. Sivananthan, SIMS and XPS characterization of CdS/CdTe heterostructures grown by MBE, Nucl. Instr. Meth. Phys.

Res. Section B: Beam Interactions with Materials and Atoms, 161-163 (2000) 975-979.

[41] J. Fritsche, A. Thiben, A. Klein, W. Jaegermann, Oriented growth and band alignment at the CdTe/CdS interface, Thin Solid Films, 387 (2001) 158-160.

[42] G.J. Russell, Practical reflection electron diffraction, Progress in Crystal Growth and Characterization, 5 (1982) 291-321.

[43] D. Litvinov, T. O’Donnell, R. Clarke, In situ thin-film texture determination, J. Appl. Phys., 85 (1999) 2151-2156.

[44] G.-C. Wang, T.-M. Lu, RHEED Transmission Mode and Pole Figures: Thin Film and nanostructure Texture Analysis, Springer, New York, (2014).

[45] G.R. Awan, A.W. Brinkman, G.J. Russell, J. Woods, New epitaxial relationships in the deposition of CdS onto CdTe, J. Cryst. Growth, 85 (1987) 477-482.

[46] A. Kanevce, D.H. Levi, D. Kuciauskas, The role of drift, diffusion, and recombination in time-resolved photoluminescence of CdTe solar cells determined through numerical simulation, Prog. Photovolt: Res. Appl., 22 (2014) 1138-1146.

[47] A.E. Abken, D.P. Halliday, K. Durose, Photoluminescence study of polycrystalline photovoltaic CdS thin film layers grown by close-spaced sublimation and chemical bath deposition, J. Appl. Phys., 105 (2009) 064515.

[48] D. Kuciauskas, A. Kanevce, J.N. Duenow, P. Dippo, M. Young, J.V. Li, D.H. Levi, T.A. Gessert, Spectrally and time resolved photoluminescence analysis of the CdS/CdTe interface in thin-film photovoltaic solar cells, Appl. Phys. Lett., 102 (2013) 173902.

[49] H. Park, G. Yang, S. Chun, D. Kim, J. Kim, CdTe microwire-based ultraviolet photodetectors aligned by a non-uniform electric field, Appl. Phys. Lett., 103 (2013) 051906. [50] Y. Ye, L. Dai, T. Sun, L.P. You, R. Zhu, J.Y. Gao, R.M. Peng, D.P. Yu, G.G. Qin, Highquality CdTe nanowires: Synthesis, characterization, and application in photoresponse devices, J. Appl. Phys., 108 (2010) 044301.

[51] X. Xie, S.-Y. Kwok, Z. Lu, Y. Liu, Y. Cao, L. Luo, J.A. Zapien, I. Bello, C.-S. Lee, S.-T. Lee, W. Zhang, Visible-NIR photodetectors based on CdTe nanoribbons, Nanoscale, 4 (2012) 2914-2919.

[52] D.P. Halliday, M.D.G. Potter, J.T. Mullins, A.W. Brinkman, Photoluminescence study of a bulk vapour grown CdTe crystal, J. Cryst. Growth, 220 (2000) 30-38.

[53] C.R. Corwine, J.R. Sites, T.A. Gessert, W.K. Metzger, P. Dippo, J. Li, A. Duda, G. Teeter, CdTe photoluminescence: Comparison of solar-cell material with surface-modified single crystals, Appl. Phys. Lett., 86 (2005) 221909.

[54] D. Kuciauskas, P. Dippo, Z. Zhao, L. Cheng, A. Kanevce, W.K. Metzger, M. Gloeckler, Recombination Analysis in Cadmium Telluride Photovoltaic Solar Cells With Photoluminescence Spectroscopy, IEEE Journal of Photovoltaics, 6 (2016) 313-318. 
[55] J.P. Enríquez, E. Gómez Barojas, R. Silva González, U. Pal, S and Te inter-diffusion in CdTe/CdS hetero junction, Sol. Energy Mater. Sol. Cells, 91 (2007) 1392-1397.

[56] K. Ohata, J. Saraie, T. Tanaka, Optical Energy Gap of the Mixed Crystal CdS xTe 1- x, Jpn. J. Appl. Phys., 12 (1973) 1641.

[57] D.W. Lane, A review of the optical band gap of thin film CdSxTe1-x, Sol. Energy Mater. Sol. Cells, 90 (2006) 1169-1175.

[58] D. Mohanty, W. Xie, Y. Wang, Z. Lu, J. Shi, S. Zhang, G.-C. Wang, T.-M. Lu, I.B. Bhat, van der Waals epitaxy of CdTe thin film on graphene, Appl. Phys. Lett., 109 (2016) 143109. [59] F. Jiang, H. Shen, J. Jiao, Formation of Photoconductive SnS Thin Films through Reaction of Sn-Metal Films in Sulfur-Vapor, ECS J. Solid State Sci. Technol., 2 (2013) 478-484.

[60] J.S. Skarman, On the relationship between photocurrent decay time and trap distribution in CdS and CdSe photoconductors, Solid·State Electron., 8 (1965) 17-29.

[61] P.K. Nair, M.T.S. Nair, J. Campos, Photocurrent response in chemically deposited CdS thin films, Sol. Energy Mater., 15 (1987) 441-452.

[62] Y.B. Yang, J.K. Dash, A.J. Littlejohn, Y. Xiang, Y. Wang, J. Shi, L.H. Zhang, K. Kisslinger, T.M. Lu, G.C. Wang, Large Single Crystal $\mathrm{SnS}_{2}$ Flakes Synthesized from Coevaporation of Sn and S, Cryst. Growth Des., 16 (2016) 961-973.

[63] T. Gao, T. Wang, Two-Dimensional Single Crystal CdS Nanosheets: Synthesis and Properties, Cryst. Growth Des., 10 (2010) 4995-5000.

[64] K.P. Acharya, J.R. Skuza, R.A. Lukaszew, C. Liyanage, B. Ullrich, CdS thin films formed on flexible plastic substrates by pulsed-laser deposition, J. Phys.: Condens. Matter, 19 (2007) 196221.

[65] K.P. Acharya, K. Mahalingam, B. Ullrich, Structural, compositional, and optoelectronic properties of thin-film CdS on p-GaAs prepared by pulsed-laser deposition, Thin Solid Films, 518 (2010) 1784-1787.

[66] K. Deng, L. Li, CdS Nanoscale Photodetectors, Adv. Mater., 26 (2014) 2619-2635.

[67] G. Yang, D. Kim, J. Kim, Self-aligned growth of CdTe photodetectors using a graphene seed layer, Opt. Express, 23 (2015) A1081-A1086.

[68] G. Yang, B.-J. Kim, D. Kim, J. Kim, Single CdTe microwire photodetectors grown by close-spaced sublimation method, Opt. Express, 22 (2014) 18843-18848.

[69] X. Wang, J. Wang, M. Zhou, H. Zhu, H. Wang, X. Cui, X. Xiao, Q. Li, CdTe Nanorod Arrays on ITO: From Microstructure to Photoelectrical Property, J. Phys. Chem. C, 113 (2009) 16951-16953.

[70] Z.-L. Zhu, L. Cui, T. Ling, S.-Z. Qiao, X.-W. Du, CdTe nanoflake arrays on a conductive substrate: template synthesis and photoresponse property, J. Mater. Chem. A, 2 (2014) 957-961.

[71] H. Sitter, J. Humenberger, W. Huber, A. Lopez-Otero, Characterization of epitaxial films of CdTe and CdS grown by hot-wall epitaxy, Sol. Energy Mater., 9 (1983) 199-206.

[72] A.L. Dawar, P.K. Shishodia, G. Chauhan, A. Kumar, P.C. Mathur, Growth of high-mobility CdS thin films, J. Mater. Sci. Lett., 9 (1990) 547-548.

[73] S. Ray, R. Banerjee, A.K. Barua, Properties of Vacuum-Evaporated CdS Thin Films, Jpn. J. Appl. Phys., 19 (1980) 1889.

[74] I. Turkevych, R. Grill, J. Franc, E. Belas, P. Höschl, P. Moravec, High-temperature electron and hole mobility in CdTe, Semicond. Sci. Technol., 17 (2002) 1064.

[75] Q. Long, S.A. Dinca, E.A. Schiff, M. Yu, J. Theil, Electron and hole drift mobility measurements on thin film CdTe solar cells, Appl. Phys. Lett., 105 (2014) 042106. 